University of Louisville

ThinkIR: The University of Louisville's Institutional Repository

Electronic Theses and Dissertations

$12-2010$

\title{
An improved simulation algorithm for the slide protection dynamometer based on RP2.
}

Julian Wallach 1982-

University of Louisville

Follow this and additional works at: https://ir.library.louisville.edu/etd

\section{Recommended Citation}

Wallach, Julian 1982-, "An improved simulation algorithm for the slide protection dynamometer based on RP2." (2010). Electronic Theses and Dissertations. Paper 1502.

https://doi.org/10.18297/etd/1502

This Master's Thesis is brought to you for free and open access by ThinkIR: The University of Louisville's Institutional Repository. It has been accepted for inclusion in Electronic Theses and Dissertations by an authorized administrator of ThinkIR: The University of Louisville's Institutional Repository. This title appears here courtesy of the author, who has retained all other copyrights. For more information, please contact thinkir@louisville.edu. 


\title{
AN IMPROVED SIMULATION ALGORITHM FOR THE SLIDE PROTECTION DYNAMOMETER BASED ON RP2
}

\author{
By \\ Julian Wallach \\ A Thesis \\ Submitted to the Faculty of the \\ Graduate School of the University of Louisville \\ in Partial Fulfillment of the Requirements \\ for the Degree of \\ Master of Science \\ Department of Industrial Engineering \\ University of Louisville \\ Louisville, Kentucky
}

December 2010 
Copyright 2010 by Julian Wallach

All rights reserved 



\section{AN IMPROVED SIMULATION ALGORITHM FOR THE SLIDE PROTECTION DYNAMOMETER BASED ON RP2 \\ By}

Julian Wallach

A Thesis Approved on

July 26, 2010

by the following Thesis Committee:

Professor Dr. William E. Biles, Thesis Director

Professor Dr. Gerald Evans

Dr. Tim Hardin

ii 


\section{ACKNOWLEDGEMENTS}

I would like to thank my advisor Professor Dr. William E. Biles for his guidance in developing my thesis and his advice in the process of writing it.

I would also like to thank my parents for their unlimited support throughout my educational and professional career. Without them, I would not be where I am today. Special thanks I would like to express to my colleagues at DB Systemtechnik. Without the advice of Dr. Peter Spiess, Sebastian Heinz, Eckhard Friebel and Jöerg Eikemeier and the support of the entire testing department for train dynamics and brakes the conclusion of this thesis would not have been possible. 


\section{ABSTRACT}

\section{AN IMPROVED SIMULATION ALGORITHM FOR THE SLIDE PROTECTION DYNAMOMETER BASED ON RP2}

\section{Julian Wallach}

July 26, 2010

Wheel Slide Protection Systems (WSP Systems) or Anti-Skid Devices for rail vehicles have to go through a series of Dynamometer tests before test runs with equipped rail vehicles are permitted. The simulation tests are performed on Wheel Slide Protection Dynamometers (WSPD). The WSPD used for the tests in this thesis is placed in the laboratory of DB Systemtechnik in Germany. The function of a WSPD and possible improvements, which have been suggested by the UIC Report 2 of the task group B164, are discussed within the thesis. One of the improvements is the implementation of adhesion curves in the simulation that are dependent of the wheel slip velocity. The implementation of this improvement in the named WSPD algorithm is explained as well the findings of a before and after test. The conclusion show that adhesion dependent wheel slip curves in the simulation algorithm of a WSPD are necessary to test a WSP Systems ability of finding the maximum adhesion during the braking process. 


\section{LIST OF TABLES}

PAGE

TAB. 6.1 Non-Wheel Slip Velocity depending Adhesion Value..............................43

TAB. 6.2 Wheel Slip Velocity dependent Adhesion Value ...................................45

TAB. 6.3 Differences between the Setting Files .....................................................46

TAB. 6.4 Statistical Evaluation of N001 and N002 compared, values in m..............53

TAB. 6.5 Braking distance $\boldsymbol{s}_{\boldsymbol{B}}$ deviation between N001 and N002..........................54

TAB. 6.6 GM Value $-v_{s} \geq 10 \%$ over total braking, comparison of N001 and N002...54

TAB. 6.7 Absolute Slip $-v_{\text {smax }}$ over total braking, comparison of N001 and N002.....55 


\section{LIST OF FIGURES}

PAGE

FIG. 2.1 Working forces on wheel and rail (left). Wheel-rail contact patch, (Wende, D. (2003)

FIG. 2.2 Velocities on a braking wheel on the track, of Wende, D. (2003)...............14

FIG. 3.1 Adhesion / Slip Characteristic curves Type A, B, C (B164 / RP2) …...........18

FIG. 3.2 Direct Method to measure Adhesion (UIC B164 RP2 (1990)) ………...........20

FIG. 3.3 Indirect Method to measure Adhesion (UIC B164 RP2 (1990)) ……...........20

FIG. 4.1 Scheme of the Wheel Slide Protection Dynamometer. (DB Systemtechnik

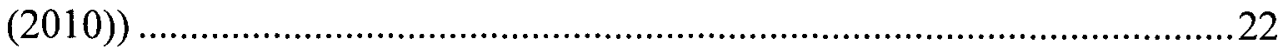

FIG. 4.2 Axle Simulation Unit of WSPD. (DB Systemtechnik (2010)) …...................24

FIG. 4.3 WSP Valve Unit (EV/HV01 ...04). (DB Systemtechnik (2010))..................26

FIG. 4.4 Brake Cylinder Unit (pC01 ...04). (DB Systemtechnik (2010)) ....................27

FIG. 4.5 Pressure Reservoir Unit (pR and pHB). (DB Systemtechnik (2010)) ..........28

FIG. 4.6 Signal Processing Units in Rack. (DB Systemtechnik (2010)) ........................30

FIG. 4.7 Simulation Computing Unit. (DB Systemtechnik (2010))..............................31

FIG. 4.8 Example of WSP Device. (DB Systemtechnik (2010)) …............................32

FIG. 4.9 Example of Simulation Code. (DB Systemtechnik (2010)) ...........................34

FIG. 4.10 Simulation Algorithm Breakdown Structure. (DB Systemtechnik (2010)).34 
FIG. 4.11 Visualization of DIAdem Program Cycle Operations. .............................35

FIG. 4.12 Manual Control Display. (DB Systemtechnik (2010)) .............................39

FIG. 4.13 Automatic Control Display. (DB Systemtechnik (2010)) .........................39

FIG. 4.14 Data Chart of a WSP Braking. (DB Systemtechnik (2010)) .....................40

FIG. 6.1 Non Wheel Slip depending Adhesion Curves. (DB Systemtechnik (2010)) .44

FIG. 6.2 Adhesion Curves depending on Wheel slip Velocity. (DB Systemtechnik

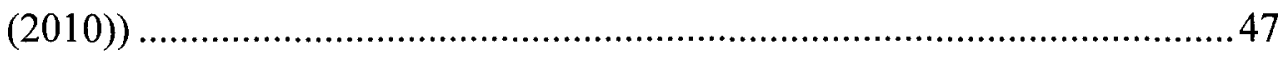

FIG. 6.3 Create new channels for mue00...99 in DAC $\backslash$ Computing. (DB

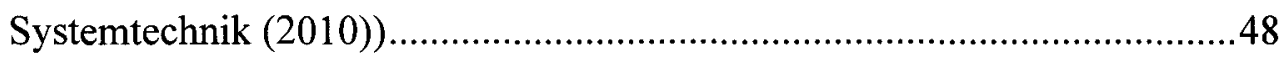

FIG. 6.4 Include channels in Settings File N002_020. (DB Systemtechnik (2010)) ...48

FIG. 6.5 Selection of mue $X X$ dependent on vs. (DB Systemtechnik (2010))..............50

FIG. 6.6 Call new Settings File "N002_020" in Excel.. (DB Systemtechnik (2010)) .51

FIG. 6.7 The two Adhesion Curves to be compared. (DB Systemtechnik (2010)).....52

FIG. 6.8 N001_070_P exemplary data chart. (DB Systemtechnik (2010))................56

FIG. 6.9 N002_020_P exemplary data chart. (DB Systemtechnik (2010)) .................57 


\section{LIST OF FORMULAS}

PAGE

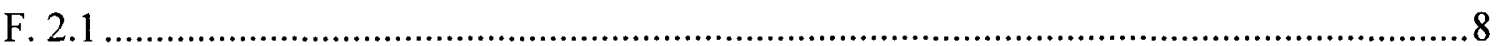

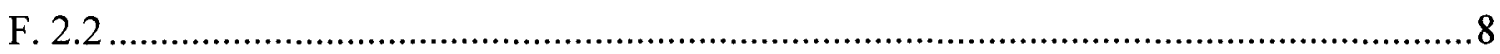

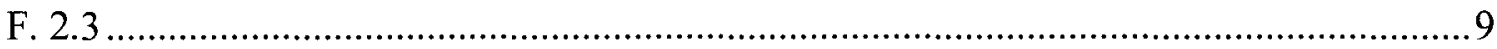

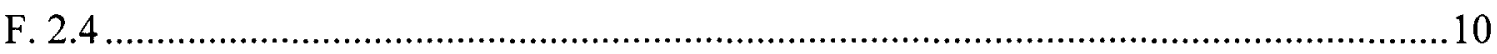

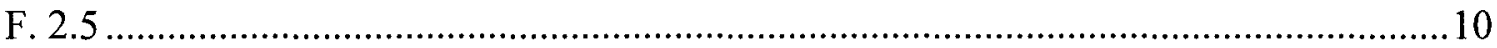

F. 2.6

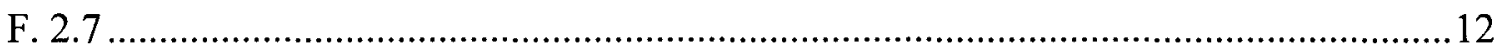

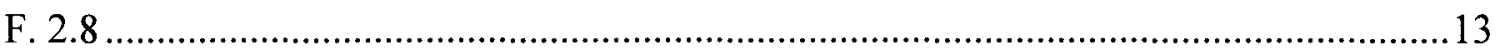

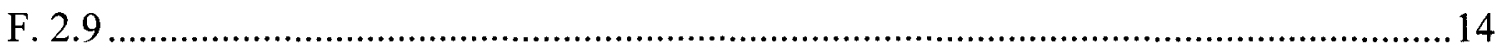

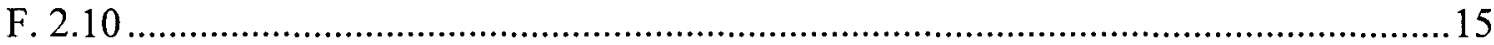

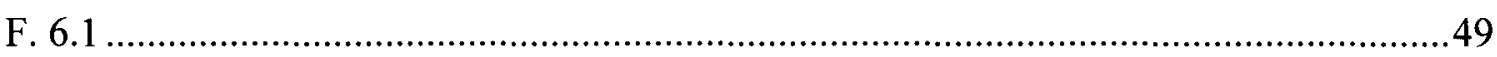




\section{TABLE OF CONTENTS}

PAGE

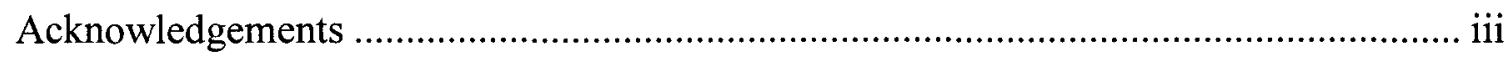

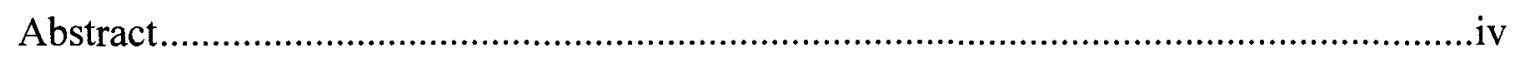

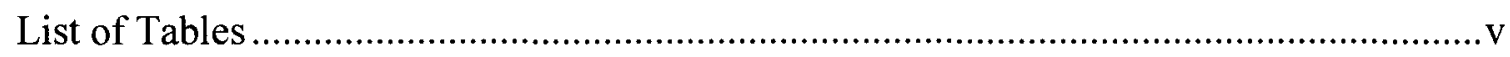

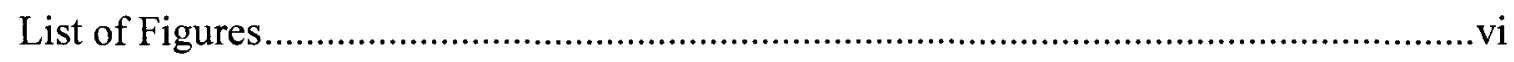

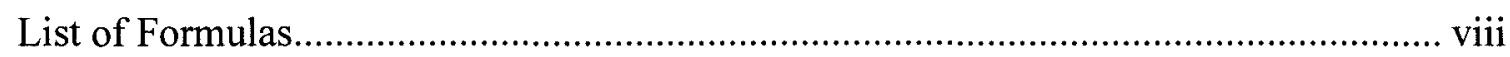

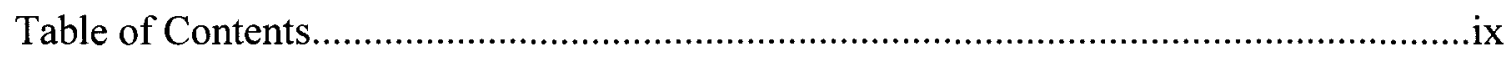

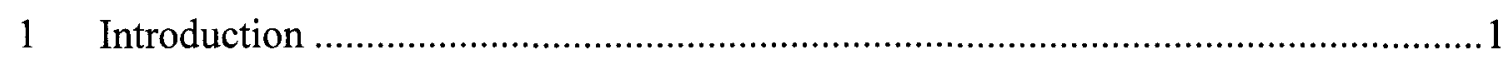

1.1 DB Systemtechnik - Test Center for Brakes and Coupling ...............................1

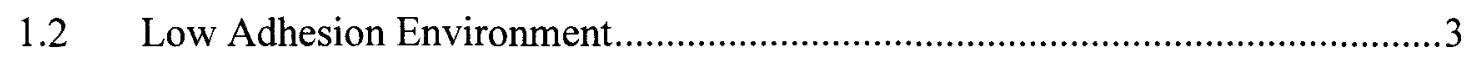

$1.3 \quad$ Wheel Slide Protection Dynamometer ……………..................................

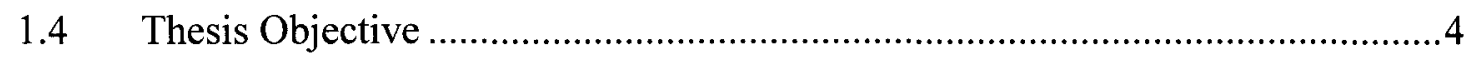

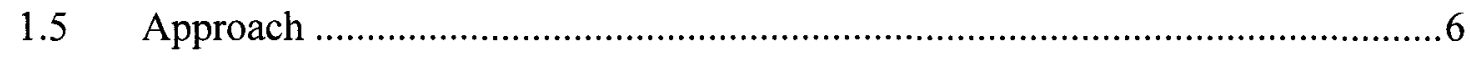

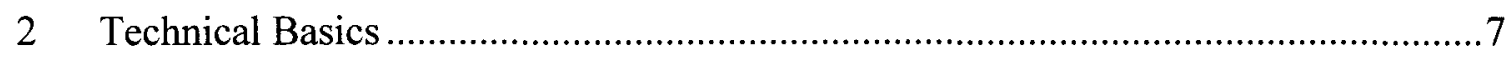

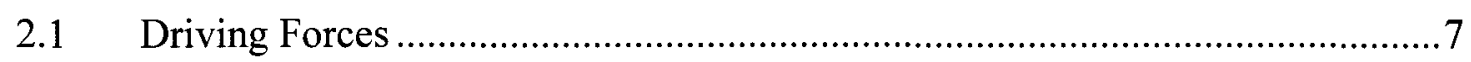

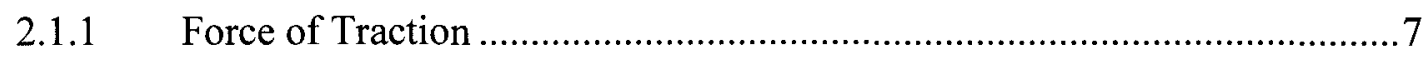

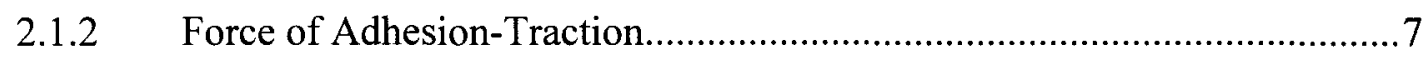

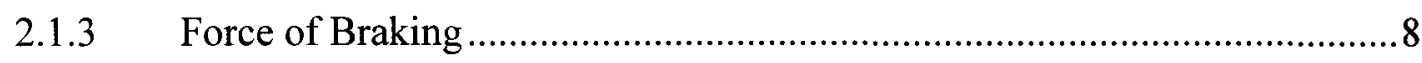




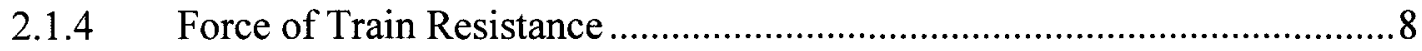

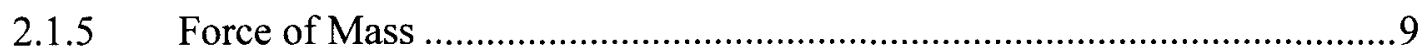

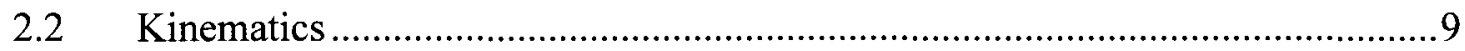

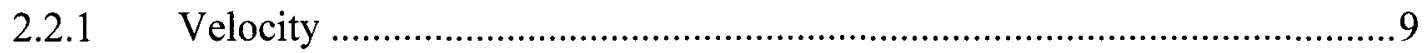

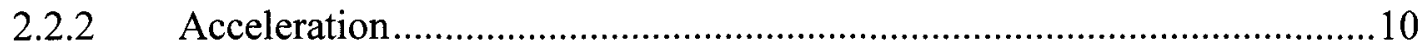

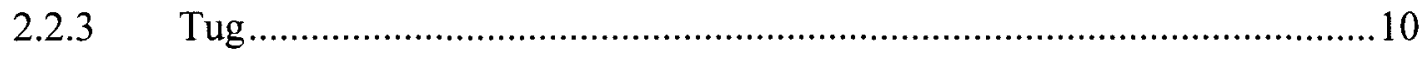

2.3 Adhesion and Brake Force ……................................................................ 11

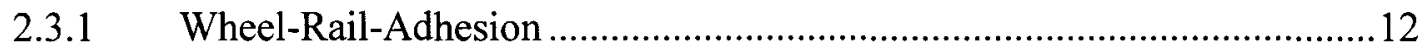

2.3.2 Adhesion Theories ............................................................................13

2.3.3 Physical Adhesion Theory ………………….........................................13

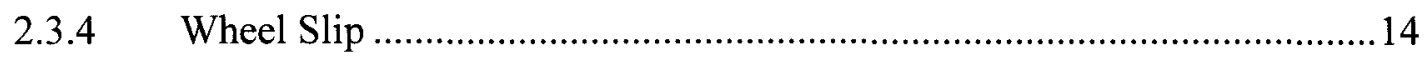

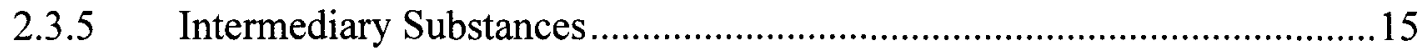

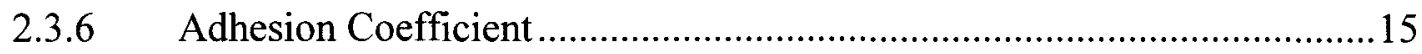

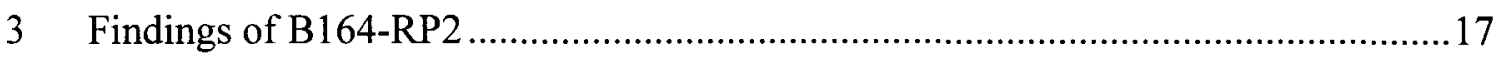

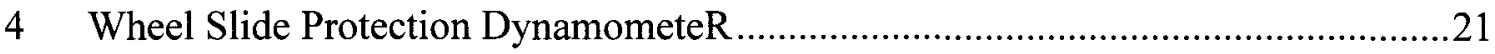

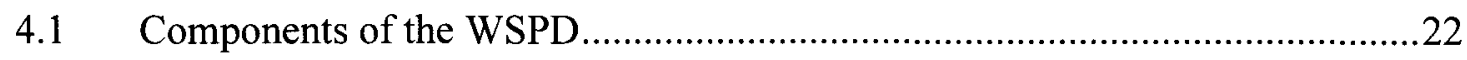

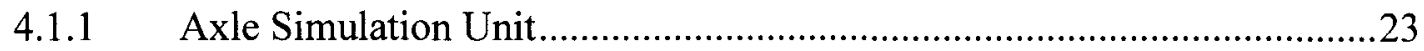

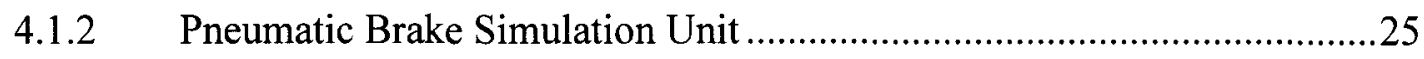

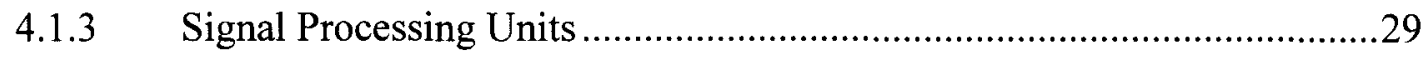

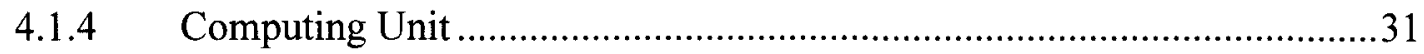

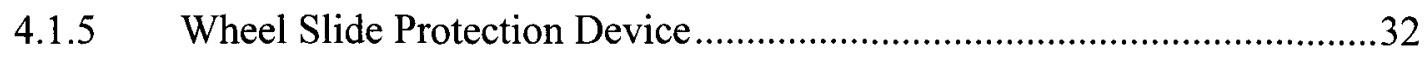

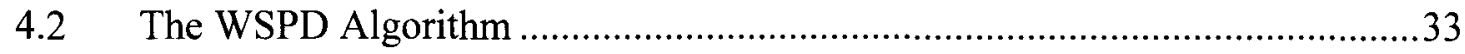

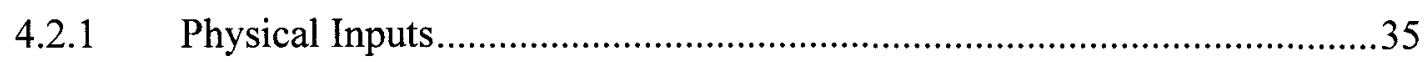




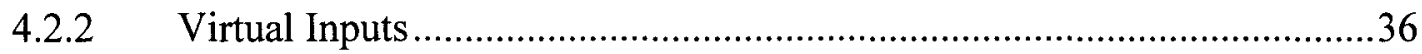

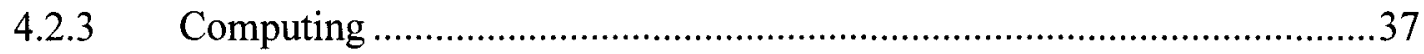

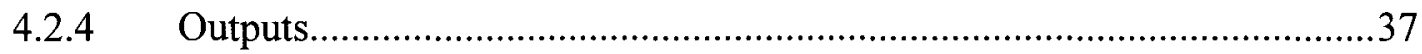

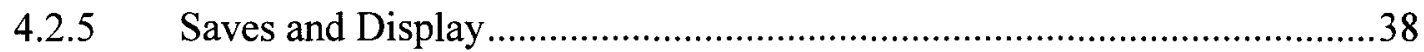

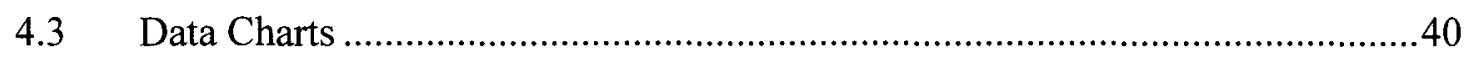

$5 \quad$ Areas for Improvement of the WSPD .................................................................

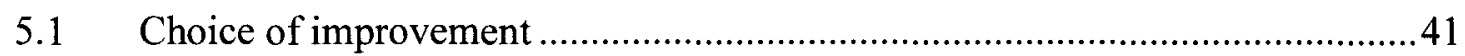

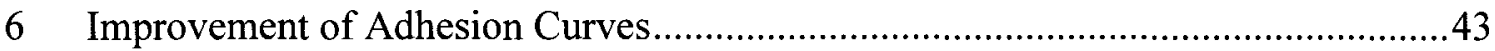

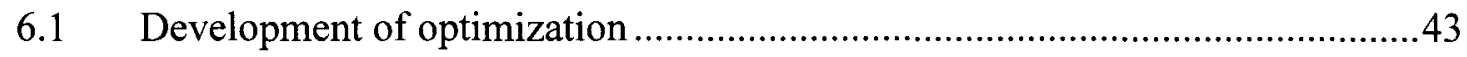

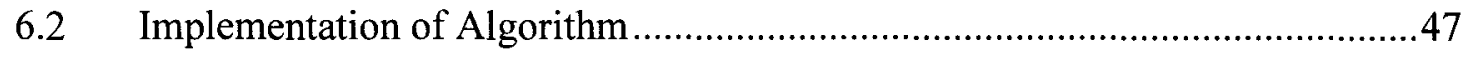

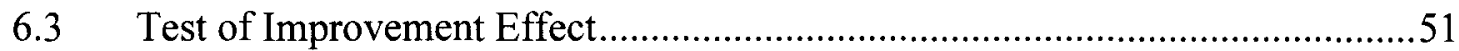

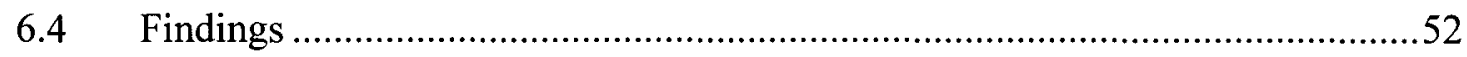

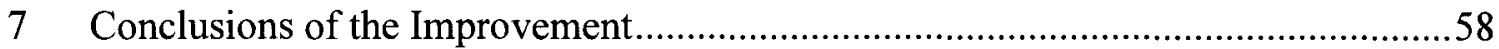

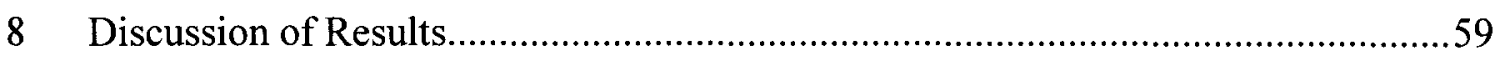

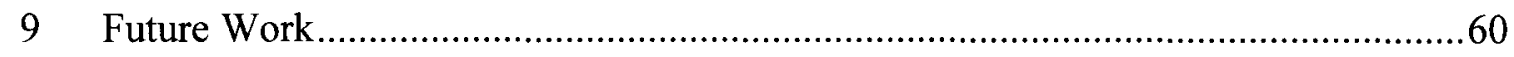

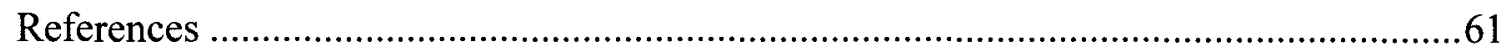

Curriculum Vitae 


\section{INTRODUCTION}

The following introduces first the company DB Systemtechnik in whose laboratory the research work for this thesis is carried out. To better understand the principal field in which anti-skid devices are applied a brief introduction to low adhesion environment is made. Later on the objective of the thesis is explained and further the approach which has been taken.

\subsection{DB Systemtechnik - Test Center for Brakes and Coupling}

Technical expertise for the integrated system...

DB Systemtechnik is the engineering centre for DB AG and it is Europe's biggest centre of excellence on railway technology. DB Systemtechnik is a high-performing, customerdriven service provider that, as well as authoritatively serving the DB Group by dint of its specialist knowledge, is also increasingly active on the global railway market. DB Systemtechnik guarantees its customers independence, neutrality and confidentiality in respect of work carried out under its Quality Management System in compliance with the stipulations and recommendations contained in DIN EN ISO 9000:2000 $\mathrm{ff}$ and the accreditation principles set forth in DIN EN ISO/IEC 17025:2000.

The Test Centre of DB Systemtechnik is responsible for tests, investigations and trials while making a key contribution towards the safe, reliable and economical use of technical production resources in operation. As a means of enabling these activities to be 
pursued independently and authoritatively, a Test Centre and an Experts Organization have been established within DB Systemtechnik. The Test Centre is recognised by the Federal Railway Authority (EBA) and is an Associated Partner of Eisenbahn Cert (EBC), the "Notified Body for Interoperability" in Germany. It has been certified by DQS $\mathrm{GmbH}$, the German association for the certification of management systems. It performs its tasks in the laboratories of the Specialist Divisions. While such tasks are being processed, specialist staff at these laboratories are answerable to the Head of the Test Centre, who also conducts the concluding formal appraisal of all test and assessment documents.

Tests and Trials of Brake Technology, Draw and Buffing Gear, Train Dynamics is the area where the work of this thesis is focused on. In the further run of this document we will speak about tests involving brakes, draw and buffing gear and train dynamics. As a result of many years of experience and of modern, rail-tested instrumentation, the services of this department are in demand by railway companies and industry at home and abroad. In addition to the standard measuring tasks, individual solutions are developed, such as providing support for the instrumentation of field trials. Measuring carriages are maintained for operational tests; a pneumatic testbed, a skid simulation testbed, a UIC-approved friction testbed and a component lining testbed are available for testing brake components. The department's facilities also permit comprehensive and complex trials to be carried out involving large numbers of measuring points.

However the focus of this research is mainly previously listed Skid Simulation Testbed, which is mostly used to test new or modified anti-skid or wheel slide protection devices in a laboratory environment before the test runs with the real rail vehicles take place. 
Some of the testing components of the braking equipment also tested on the Simulation Testbed are brake controllers, anti-skid components, magnetic rail and eddy current brakes, sand distributors, and emergency brake bypass/electro-pneumatic brake equipment for UIC or EC approval, and as demonstration of fitness for railway use.

\subsection{Low Adhesion Environment}

The maximal traction respectively braking force that can be exercised by a rail vehicle is dependent on the maximal force that can act on the contact patch between the wheel sets of the train and the rail head. In a dry and clean laboratory environment these forces and coefficient are relatively closely computable. Whereas in natural environment a few more factors can influence the reaction in the contact patch. The most characteristic of these are temperature, material of wheel and rail, velocity, and intermediate materials inbetween wheel and rail. All these factors can strongly influence the adhesion in the traction and braking process. The thesis at hand will however concentrate on adhesion during braking.

What has made the railway transportation interesting and advantageous in on place leads to problems in another. Taking the advantage of low friction and thereby moving heavy loads energy efficiently causes the problem once we want to get the load in or out the moving state. A train can only brake as quickly as the adhesion permits.

Over the past decades the European railways have invested much time to study the effects of variation in adhesion on the railway systems. Especially every year in autumn the falling tree leaves on the tracks cause multiple incidents where the train drivers simply can not get their train to brake anymore. Reason for that is a sudden decline in adhesion which is commonly referred to as "Low Adhesion Environment". The wet leave, when 
crushed between the wheel and rail, form a very slippery carbon based medium that drops the adhesion closely down to zero.

The effects of low adhesion environments have been and are being studied in laboratory environments and various test runs in the field. The "Wheel Slide Protection Dynamometer" or "Skit Testbed" at DB Systemtechnik is used to run laboratory based tests in the field of low adhesion.

\subsection{Wheel Slide Protection Dynamometer}

The Wheel Slide Protection (WSP) Dynamometer of DB Systemtechnik is part of the laboratory facilities of the department Brakes and Couplings. On the dynamometer new and modified anti-skit devices to can be tested to be built into new or modified trains afterwards. The dynamometer consists of a computing unit, an axle / wheel set simulation unit, and a pneumatic train brake simulation unit. The anti-skid device will be delivered of its manufacturer who also provides the information on which protocol the tests should be based or if the test are of a research and development nature. On most occasions a mixture of both is the case. The data of the laboratory test will be analyzed and used as a basis to decide weather the anti-skid device can be tested in field test runs, where it will be built into the train type in which it is supposed to find its future use.

A more thorough description of the single parts of the WSP Dynamometer will follow in chapter 4.

\subsection{Thesis Objective}

Today the European wheel slide protection systems of rail vehicles are optimized to fulfill the requirements of the norms set by the "International Union of Railways" (UIC). 
The report "RP2" indicates that a protection system being tested on detergent prepared tracks, according to the "UIC 541-05" norm, is insufficient in an extremely low adhesion environment as it is present in fall every year.

The title of this thesis is "An improved simulation algorithm for the slide protection dynamometer based on RP2", which derives form the following subject:

The Subject of this Master Thesis will be the development of an improved simulation at the wheel slide protection dynamometer by including the optimization instructions indicated in the RP2 report of the UIC task group B164. The validation of the improved simulation is supposed to be the basis for an actual-theoretical comparison on the basis of actual test run results versus simulated dynamometer results which is to follow in future. As part of the optimizations of the WSP Dynamometer algorithm the before improvement and after improvement results of then will be compared. The comparison is to point out the benefits of the new algorithm by indicating the accuracy of the simulation.

Although rail vehicles have been built for more than 150 years there are many phenomena still not fully explained, such as the changing adhesion coefficient during the braking process due to variation in speed, temperature, mix of friction partners and addition of liquids and other random materials and so forth. The goal of this Master Thesis is to help define the relevant variables in the braking and wheel slide protection process. Further more the influence of these variables on each other and more importantly the brake distance of the train will then easier to be qualified. The goal of this Master Thesis is to define the relevant variables in the braking and wheel slide protection process based on the information of RP2 and include some more of them in the simulation of the WSP Dynamometer. This will later on help to learn more about the influence of these 
variables on each other and more importantly the brake distance of the train which accordingly could be qualified.

\subsection{Approach}

To achieve the objective, the function of rail vehicles has to be understood, whereupon the focus will be the braking system of passenger trains and their wheel slide protection systems. A brief assembly of the factors which are most important to the function of rail vehicles and their anti-skid devices will be given in the basics of chapter 2 .

The RP2 report has to be analyzed. Based on this analysis the simulation program at hand will have to be adapted accordingly. Chapter 3 will hold the findings of RP2.

The main resource to implement the research and test the optimized algorithm will be the dynamometer in the brake laboratory of DB Systemtechnik which will be more thoroughly explained in chapter 4 .

Further the possible areas of improvement of the WSP Dynamometer algorithm will be stated in chapter 5 , followed by the choice of the optimizations to be handled within this thesis. The implementation of the chosen improvements will be elucidated in chapters 6 . Afterwards follows the conclusion of the improvements and the discussion of the results also referring to future work in chapters 7,8 , and 9 .

Next to the ordinary sources of information, the profound experience in the trail department and the extensive number of documented test runs will provide the basis for the theoretical background of this work. 


\section{TECHNICAL BASICS}

This chapter shall give an overview of the principal physical interrelationships which are necessary to better understand the train dynamics, low adhesion environment and antiskid devices.

\subsection{Driving Forces}

Driving Forces are those forces which come in to play when a train is to move forward, brake and so on. For reasons of simplification in this thesis only translational forces in the direction of the train movement are considered. Curves and other side forces will be neglected.

\subsubsection{Force of Traction}

The course of the trains movement is controlled through the force of traction. The corresponding movement condition can be set in place, changed, and conserved by the control of traction. In the following the force of traction is called $\boldsymbol{F}_{T}$. It is measured in $\mathrm{kN}$ (Wende, D. (2003)).

\subsubsection{Force of Adhesion-Traction}

The Force of Adhesion Traction is based on the friction law of Coulomb. It says that the force of traction $F_{T}$ can only be as high as the product of the Adhesion Coefficient $\mu$ 
times the Normal Force $N$ respectively the Weight $\boldsymbol{W}$ of the train or wheel set. This results in the following Formula:

$$
F_{T}=\mu * W
$$

$F_{T} \ldots \quad$ Force of Traction in $\mathrm{kN}$

$W \ldots$ Weight of train in $\mathrm{kN}$

$\mu \ldots \quad$ mean Adhesion Coefficient, dimension unit 1

\subsubsection{Force of Braking}

The Force of Braking $\boldsymbol{F}_{\boldsymbol{B}}$ is used for decrease of velocity respectively to stop the train. On down hill routes it is used to maintain the velocity and at halt to lock against unintended setting in motion. Ordinarily it is developed by wheel braking constructions and thus actuated by adherence. $\boldsymbol{F}_{\boldsymbol{B}}$ usually is negative to the movement of the train. Apart from that it equals to the force of traction and thereby results in the following formula:

$$
F_{B}=\mu * W
$$

$F_{B} \ldots \quad$ Force of Braking in $\mathrm{kN}$

$W \ldots \quad$ Weight of train in $\mathrm{kN}$

$\mu \ldots \quad$ Mean Adhesion Coefficient, dimension unit 1

\subsubsection{Force of Train Resistance}

The Force of Train Resistance is called $\boldsymbol{F}_{\boldsymbol{R} T}$ and is measured in $\mathrm{kN}$. It is the sum of all resisting forces which are opposite to the horizontal motion of the train. These forces combine various physical processes, especially friction and aerodynamics. They are displayed as a sum force and based on statistics of test results (Wende, D. (2003)). 


\subsubsection{Force of Mass}

The Force of Mass is called $\boldsymbol{F}_{\boldsymbol{M}}$, also measured in $\mathrm{kN}$, is provoked by the mass inertia of the train as a result of non-linear movement (physical law of inertia). Because of the two possible directions of change in velocity it also has two possible algebraic signs. When the velocity increases $\boldsymbol{F}_{M}$ is negative and when the velocity decreases (braking) it is positive (Wende, D. (2003)).

\subsection{Kinematics}

There are some important variables describing the movement of the train. These variables are Velocity (speed), Acceleration and Tug. The Velocity and the Acceleration are very important variables and are part of every measuring chart.

\subsubsection{Velocity}

The condition of movement $\boldsymbol{v}$, velocity, is the change of distance $\boldsymbol{s}$ over time $\boldsymbol{t}$. The infinite decimal change of distance is $\boldsymbol{d s}$ and an infinite decimal change of time is $\boldsymbol{d t}$. Thus resulting into the following formula:

$$
v=\frac{d s}{d t}
$$

$v \ldots \quad$ Velocity, in $\mathrm{m} / \mathrm{s}, \mathrm{km} / \mathrm{h}$ is possible

$s \ldots \quad$ Distance traveled in $\mathrm{m}$

$t \ldots \quad$ Time, in $\mathrm{s}$

Velocity is always positive. A negative value is not possible. It is also acceptable to use the incoherent measurement unit $\mathrm{km} / \mathrm{h} .1 \mathrm{~km}$ is equal to $1000 \mathrm{~m}$ and $1 \mathrm{~h}$ is equal to 3600 s. This results in the following connection: 


$$
1 \frac{m}{s}=3,6 \frac{\mathrm{km}}{\mathrm{h}} \text { or } 10 \frac{\mathrm{m}}{\mathrm{s}}=36 \frac{\mathrm{km}}{\mathrm{h}}
$$

\subsubsection{Acceleration}

Acceleration is the change in the condition of movement $v$. It is called $a$. The change in the condition of movement, momentary acceleration, is the potential of infinite decimal change of velocity $\boldsymbol{d} \boldsymbol{v}$ in the infinite decimal of time $\boldsymbol{d t}$. This leads to the formula:

$$
a=\frac{d v}{d t}
$$

a... Acceleration, in $\mathrm{m} / \mathrm{s}^{2}$

$v$... Velocity, in $\mathrm{m} / \mathrm{s}, \mathrm{km} / \mathrm{h}$ is possible

$t \ldots \quad$ Time, in $\mathrm{s}$

Acceleration can lead as well to an increase of velocity as to a decrease. When increasing the velocity $a$ is positive and negative when decreasing it. In the context of braking test runs a will usually lead to $a$ decrease of velocity and is thereby given as a negative value (Wende, D. (2003)).

\subsubsection{Tug}

Tug is the derivative of the acceleration over time. Most of the newer anti-skid devices are using it to gather information of the actual status of the wheel set. Since it is the second derivative of the velocity over time it also is a rather fluttery and unstable signal when the measured wheel set is not very inert (heavy).

The change in the change of movement condition, so to say, is given by the infinite decimal change of a over the infinite decimal change of time. Thus the following formula: 


$$
u=\frac{d a}{d t}
$$

$u \ldots$ Tug, in $\mathrm{m} / \mathrm{s}^{3}$

a... Acceleration, in $\mathrm{m} / \mathrm{s}^{2}$

$t \ldots \quad$ Time, in $\mathrm{s}$

Tug is not a physical standard variable yet, although already used in many calculation. The given variable $u$ may vary depending on the persons including it in their calculations (Wende, D. (2003)).

\subsection{Adhesion and Brake Force}

The Adhesion and Brake Force determine together weather a train or coach will be able to stop in sufficient short braking distance or not. Under the influence of the normal force $N$ of the axles the elastic bodies of wheel and rail build a contact patch, on which tangential forces are transmitted. This is based on Coulomb's Law of Friction.
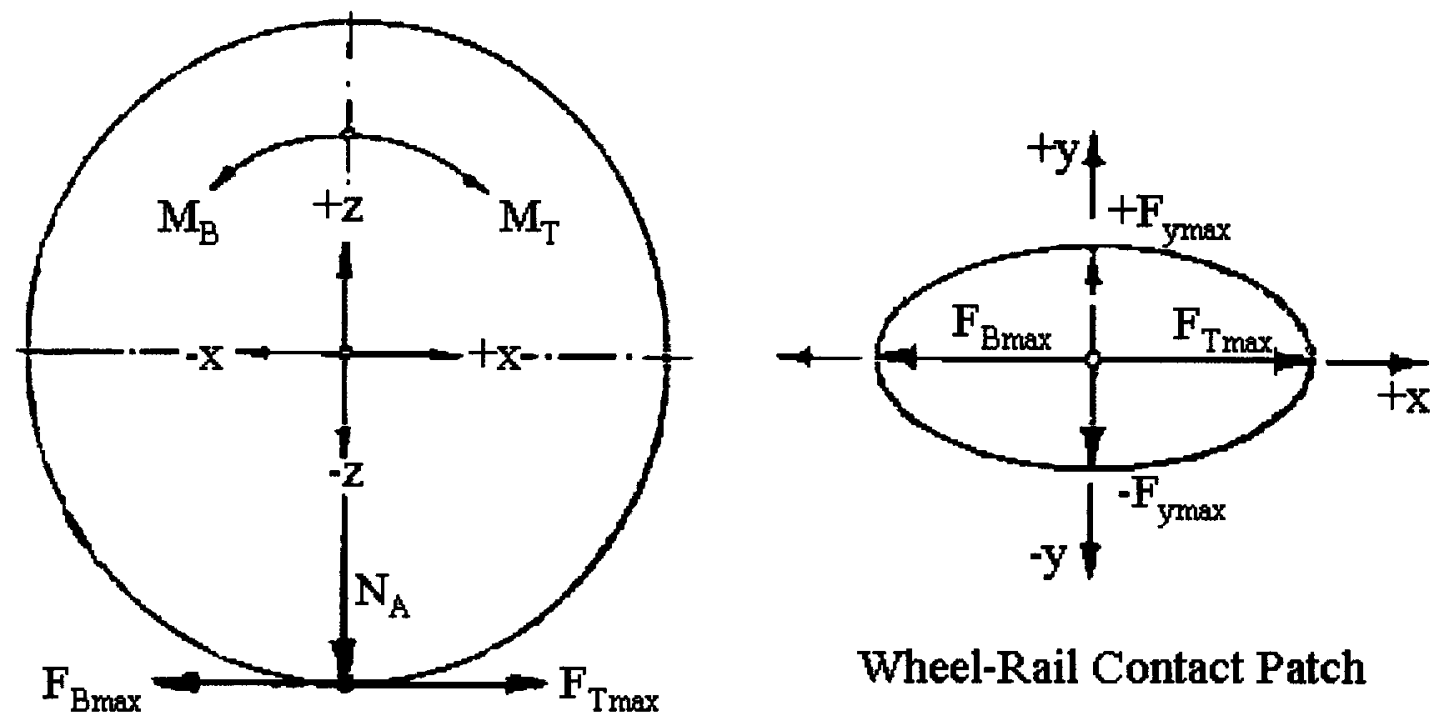

\section{Wheel-Rail Contact Patch}

FIG. 2.1 Working forces on wheel and rail (left). Wheel-rail contact patch, (Wende, D. (2003). 
The Axle Normal Force $N_{A}$ in FIG. 2.1 is exercised out of the center of gravity on to the contact patch. $N_{A}$ is equal to the weight of the axle $\mathrm{W}_{A}$. It is vertical to both the Force of Traction $F_{T}$ and the Force of Braking $F_{B}$, which are either in direction of the trains movement or opposite to it (Wende, D. (2003)).

\subsubsection{Wheel-Rail-Adhesion}

The development of either force of traction or force of braking is possible both autonomous and non-autonomous.

When the operation is autonomous each wheel set develops its proper longitudinal force. The maximal longitudinal force of the vehicle with $n$ participating axles to the adhesion results in the following:

$$
F_{B}=\sum_{i=1}^{i=n} \mu_{B i} * W_{A i}
$$

$F_{B} \ldots \quad$ Force of Braking, in $\mathrm{kN}$

$\mu_{B} \ldots \quad$ Developable adhesion during braking, dimensional unit 1

$\mathrm{W}_{A} \ldots$ Weight of axles, in $\mathrm{kN}$

Every coach and locomotive with individually braked wheel sets corresponds to an autonomous system.

When the operation is non-autonomous the tangential force on all $i$ axles is regulated to be the same independent of the maximal individual $\mu_{B}$ and $\mathrm{W}_{A}$ values. The restriction of $F_{B}$ is set by the first axle that reaches the maximal adhesion. An example for a nonautonomous system would be a locomotive with coupled axles. The formula here is a little bit simpler: 


$$
F_{B \max }=\mu_{B} * W_{A}
$$

$F_{B m a x} \ldots$ Maximal Force of Braking, in $\mathrm{kN}$

$\mu_{B} \ldots \quad$ Developable adhesion during braking, dimensional unit 1

$\mathrm{W}_{A} \ldots$ Weight of axles, in $\mathrm{kN}$

\subsubsection{Adhesion Theories}

The physical restraints given through the adhesion coefficient and its maximal exploitation are a field of high importance, given that they form the performance barrier to the traffic system railway. For this reason are these two variables matter of considerable scientific research. As a result of that two theoretical mainstreams have formed. One is the Physical Adhesion Theory and one is the Statistical Adhesion Theory. Due to a different focus in this thesis it will only be looked closer on the former of both. The latter however could come into play in the future work for which this document give already an introduction to (Wende, D. (2003)), (Lehna, H, Mahr, A. $(2005))$.

\subsubsection{Physical Adhesion Theory}

This theory is based on research of many important names in such as Kother, Curtius, Metzkow, Kalker, Kraft, Frederich, Weber and Ćap. Here the adhesion coefficient is considered as a discrete value as a result to the basics of physics. Part of this theory is the definition of Wheel Slip, which is to be explained in the next point. Further the influence of Intermediary Substances are explained as well as the Adhesion Coefficient (Wende, D. (2003)). 


\subsubsection{Wheel Slip}

For the definition of Wheel Slip three important variables are to be considered. One is the velocity of the vehicle over ground $\boldsymbol{v}_{v}$, also known as the translational speed of the vehicle. The second is the perimeter velocity of the wheel set $\boldsymbol{v}_{\boldsymbol{p}}$, which is taken on furthest point of the diameter of the wheel of at the contact point of the wheel to the rail. Last but not least, the third is the slip velocity $\boldsymbol{v}_{\boldsymbol{s}}$, which describes the deviation of the perimeter velocity to the velocity over ground. These variables are visualized in FIG. 2.2 below.

\section{Braking}

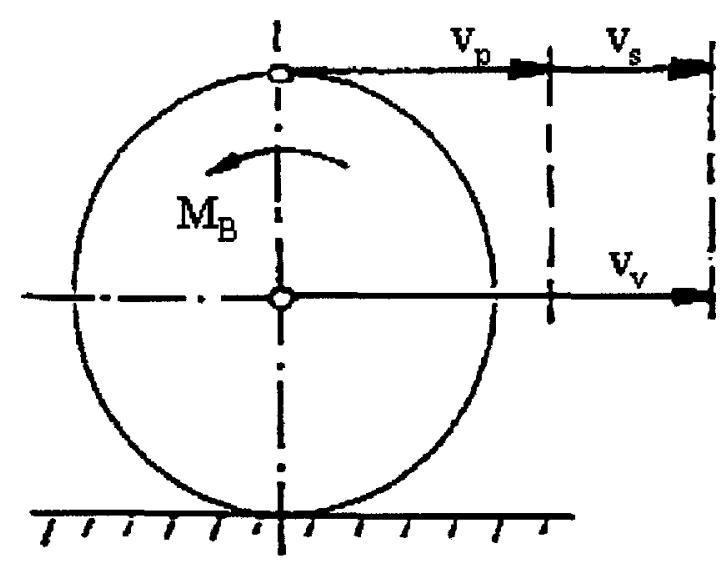

FIG. 2.2 Velocities on a braking wheel on the track, of Wende, D. (2003).

The braking slip $\sigma$ is the quotient of slip velocity and perimeter velocity. For the braking wheel we can deduct the following formulas:

$$
\begin{aligned}
& v_{s}=v_{v}-v_{p} \\
& \sigma=\frac{v_{s}}{v_{v}} \text { or } \quad \sigma=1-\frac{v_{p}}{v_{v}}
\end{aligned}
$$

$v_{p} \ldots$ Velocity of the wheel perimeter, in $\mathrm{m} / \mathrm{s}, \mathrm{km} / \mathrm{h}$ is possible

$v_{v} \ldots$ Velocity of the vehicle over ground, in $\mathrm{m} / \mathrm{s}, \mathrm{km} / \mathrm{h}$ is possible 
$v_{s} \ldots \quad$ Velocity of the wheel $\mathrm{slip}$, in $\mathrm{m} / \mathrm{s}, \mathrm{km} / \mathrm{h}$ is possible

$\sigma \ldots \quad$ Braking slip, dimension unit 1

The range in which the Braking slip can be is between 0 and 1:

$$
0 \leq \sigma \leq 1
$$

\subsubsection{Intermediary Substances}

The surface of the rail can be covered with an Intermediary Substance. These substances usually are a mix of various elements of the environment. These can be pure water, lubricious substances such as water-dust mixtures, leaves, oil and so on. They can also be rust, sand and others. What they all have in common is that they influence the adhesion by getting into the wheel-rail contact patch.

When water and lubricious substances enter the contact patch they will form a wedge of forward pushed liquid. This wedge will be driven further into the patch depending on the height of the medium and the velocity of the vehicle. The ability of the wheel to keep contact to the micro-hills, which are contact points of the friction force, is depending on the weight of the wheel and the size of the contact patch. The ability to keep the contact and exercise braking force can be more then ten times less on a wet and lubricious rail than on a dry and clean one (Wende, D. (2003)).

\subsubsection{Adhesion Coefficient}

The Adhesion Coefficient $\mu$ describes the maximum adhesion that can be exploited between wheel and rail during the braking process. This coefficient has the dimensional 
unit 1 . The normal adhesion coefficient of a dry and clean tracks lies somewhere between 0,1 and 0,3 . However when intermediary substances come to play it may drop lower than 0,03 what then is called extremely low adhesion.

The main parameters influencing $\mu$ are the following:

- technical parameters of wheel and rail

- velocity of the vehicle over ground $v_{v}$

- $\quad$ slip velocity $v_{s}$

- side forces on the wheel set

- intermediary substances

- the condition of the material tension at the contact patch

All these parameters influence the adhesion coefficient in a more or less severe order. In this thesis the parameters mainly focused on will be $v_{v}, v_{s}$, and the intermediary substances (Wende, D. (2003)). 


\section{FINDINGS OF B164-RP2}

B164 was a task group of the International Union of Railways (Union Internationale des Chemins de Fer, "UIC") to discuss and implement research to the topic "Adhesion during braking - anti-skid devices". The major findings have been concluded in the Report No. 2 "RP2".

Aim of the RP2 / B164 was the investigation of adhesion during braking of rail vehicles, more precisely passenger train coaches. It was the requirement to optimally exploit the available adhesion and meanwhile achieve optimal (shortest) braking distances while avoiding to damage the wheel treads. In the second phase the laws of adhesion and the influence of adhesion parameters were further to be researched. In order to do that measurements and test runs took place in Germany, realized by the Deutsche Bahn "DB", and also in France, realized by the Société Nationale de Chemins de Fer "SNCF". These measurements have then been evaluated to various criteria. The following essential findings could thereby concluded.

Adhesion is dependent on relative wheel slip. This dependence is created by the parameters initial adhesion, translation velocity and sliding energy developed at the wheel-rail contact patch. The natural law of adhesion comes in to play when a wheel set undergoes sudden deceleration and hence the sliding energy is negligible. According to this law the adhesion reaches its maximum approximately at $1 \%$ wheel slip. Until that 
maximal point the adhesion increases proportional to the wheel slip. In the resuming course until the wheel is locked the adhesion decreases to $50 \%$ of the maximum value. The first maximum $\left(\mathrm{S}_{1}, \mathrm{f}_{\mathrm{x} 1}\right)$ equates existent adhesion, which can be manipulated through the concentration of the detergent-solution and which drops with higher velocity. The Report 2 of B164 defines this characteristic curve as Type A.
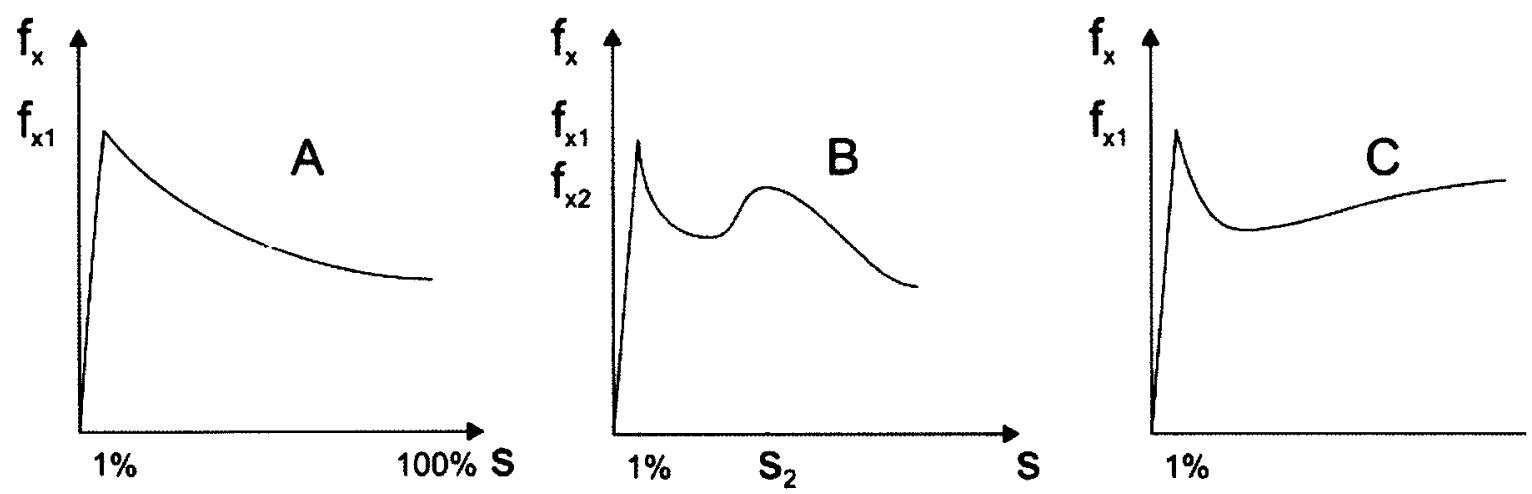

FIG. 3.1 Adhesion / Slip Characteristic curves Type A, B, C (B164 / RP2)

The released energy during the slip, "sliding energy", affects the natural adhesion / wheel-slip function. At 10\% slip no further reduction in adhesion occurs, but rather light hike can be noted. This hike ascents to a second maximum $\left(\mathrm{S}_{2}, \mathrm{f}_{\mathrm{x} 2}\right)$ with a smooth top between $15 \%$ and $30 \%$. The adhesion descends with higher slip values further again. This characteristic curve is called "Type B" in RP2 of B164.

Adhesion turns to a continuous rising slope in some cases (Type C). The cartesian coordinates of the second maximum depend on the initial adhesion value and the translation speed of the vehicle. The smaller the initial adhesion value the more severe the slip $S_{2}$ in the second maximum. The $f_{x 2}$ adhesion merges to $f_{x 1}$ adhesion when the optimal slip values $S_{2}$ are small. Hence there is no contradiction between braking on dry tracks and braking on low adhesion. The cumulative percentage to which one of these 
characteristic adhesion functions have been measured is depending on the mean wheel set deceleration. In the second test series the build up time of the braking force has been set up so that mostly Type B occurred. In RP2 it is emphasized that the sliding energy can provoke a rapid regaining of adhesion. The adhesion can double itself within 10s. The adhesion drops to its original value once without this energy. Also, when the sliding energy is too high the adhesion drops to a lower level. It is especially pointed out that the sliding energy remains the same in the product of optimal differential speed and optimal adhesion, while being independent of the translation speed of the vehicle. In RP2 of B164 the sliding energy is stated to be the energy which is transformed to slipping power on the contact patch in the time from the beginning of the braking to the reaching of the second maximum. The product of optimal adhesion and optimal differential speed grows asymptotically with the slipping energy.

The empiric foundation of these findings is based on direct and indirect measurements. In the direct method the entire adhesion / slip function is run through within $8 \mathrm{~s}$. Whereas the translation speed is kept constant (FIG. 3.2). The mean deceleration is calculated by averaging the deceleration at slip values of $10 \%, 20 \%, 30 \%$ and $40 \%$. To produce Type B adhesion curves the mean deceleration was set lower than $15 \mathrm{~m} / \mathrm{s}^{2}$. Analyzing the measurements has shown that the adhesion was usually lower when loosening the brakes than when tightening the brakes at the start (Viereck, U. (2007). 

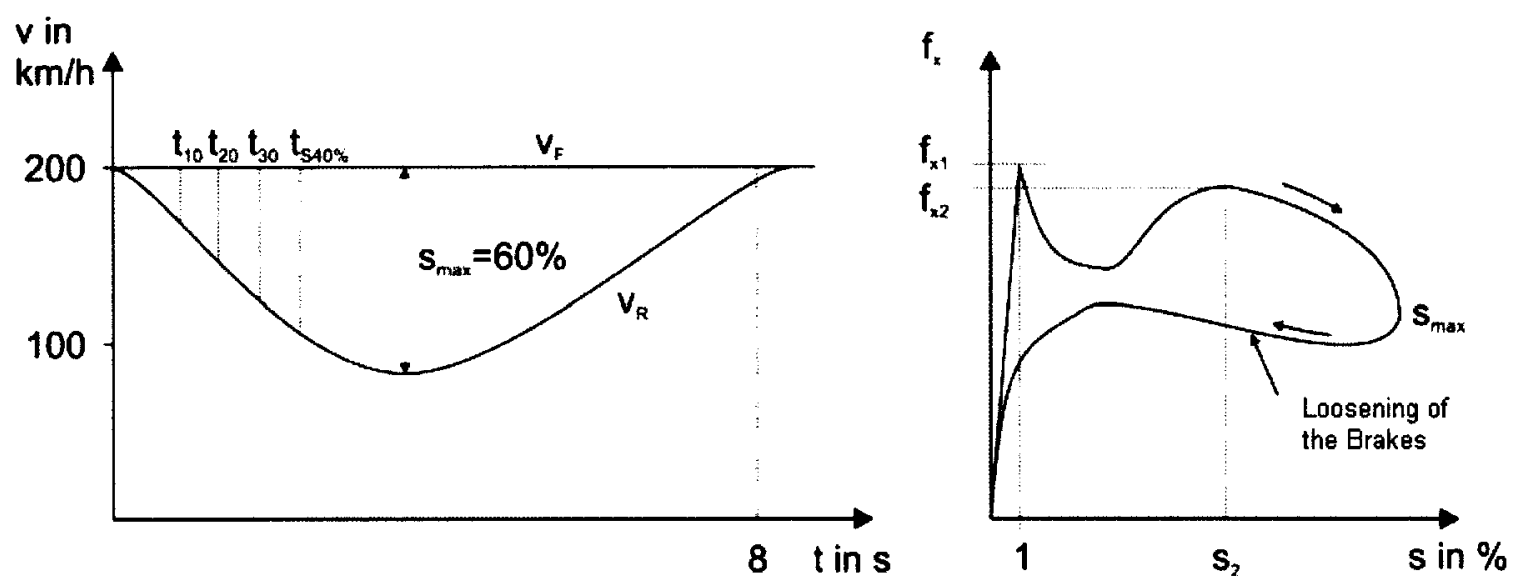

FIG. 3.2 Direct Method to measure Adhesion (UIC B164 RP2 (1990))

In the indirect method a predefined slip is run-up each time. This leads to a point wise recording of the adhesion / slip function (FIG. 3.3). The difference to the direct method is that the slip is held constant for $4 \mathrm{~s}$ before the brake is loosened. Due to the fact that it takes a second to reach the target slip the adhesion is extrapolated to the time zero. This produces curves which equal those of the direct method in their characteristic. During this way of measuring is the adhesion mostly higher when loosening the brakes compared to the adhesion when tightening them. (UIC B164 RP2 (1990)).
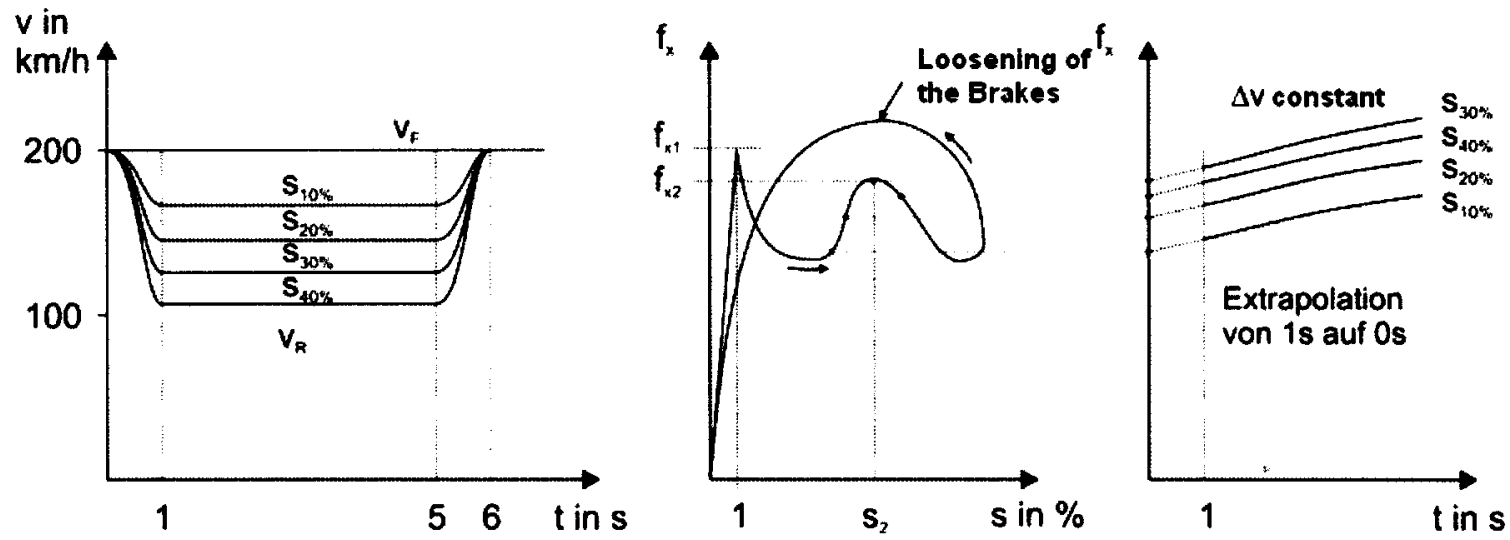

FIG. 3.3 Indirect Method to measure Adhesion (UIC B164 RP2 (1990)) 


\section{WHEEL SLIDE PROTECTION DYNAMOMETER}

The Wheel Slide Protection Dynamometer "WSPD" is located in the laboratory facilities of DB Systemtechnik. It is used to conduct research on wheel slide protection devices, also known as anti-skid devices. When it is not research that is carried out, then the WSPD is the medium to test new or modified WSP devices according to national and international standards. It consists of an axle simulation unit, a pneumatic brake simulation unit, signal processing units, a computing unit and the wheel slide protection device to be tested on the dynamometer.

The main task of the WSPD is to simulate a train, locomotive, or passenger coach running along a course for a braking test. The aim is to physically give the tested WSP device the impression it would really be on the vehicle. It is therefore vital to the tests on the WSPD to make sure that the deviation to the signals measured on a real test run is as small as possible. Obviously there will always be a slight difference to the real thing! But if that occurs it is important to know as detailed as possible in what range the deviation is. This chapter will give an overview on how the WSPD works and what the gathered data after a simulation looks like. The aim is to provide fundamental understanding for the following subjects to be discussed. 


\subsection{Components of the WSPD}

The parts of the WSPD are all working independently. However the heart of the ensemble is the computing unit followed by the testee, the WSP device. The scheme in FIG. 4.1 gives an overview on how the single components are connected to each other.

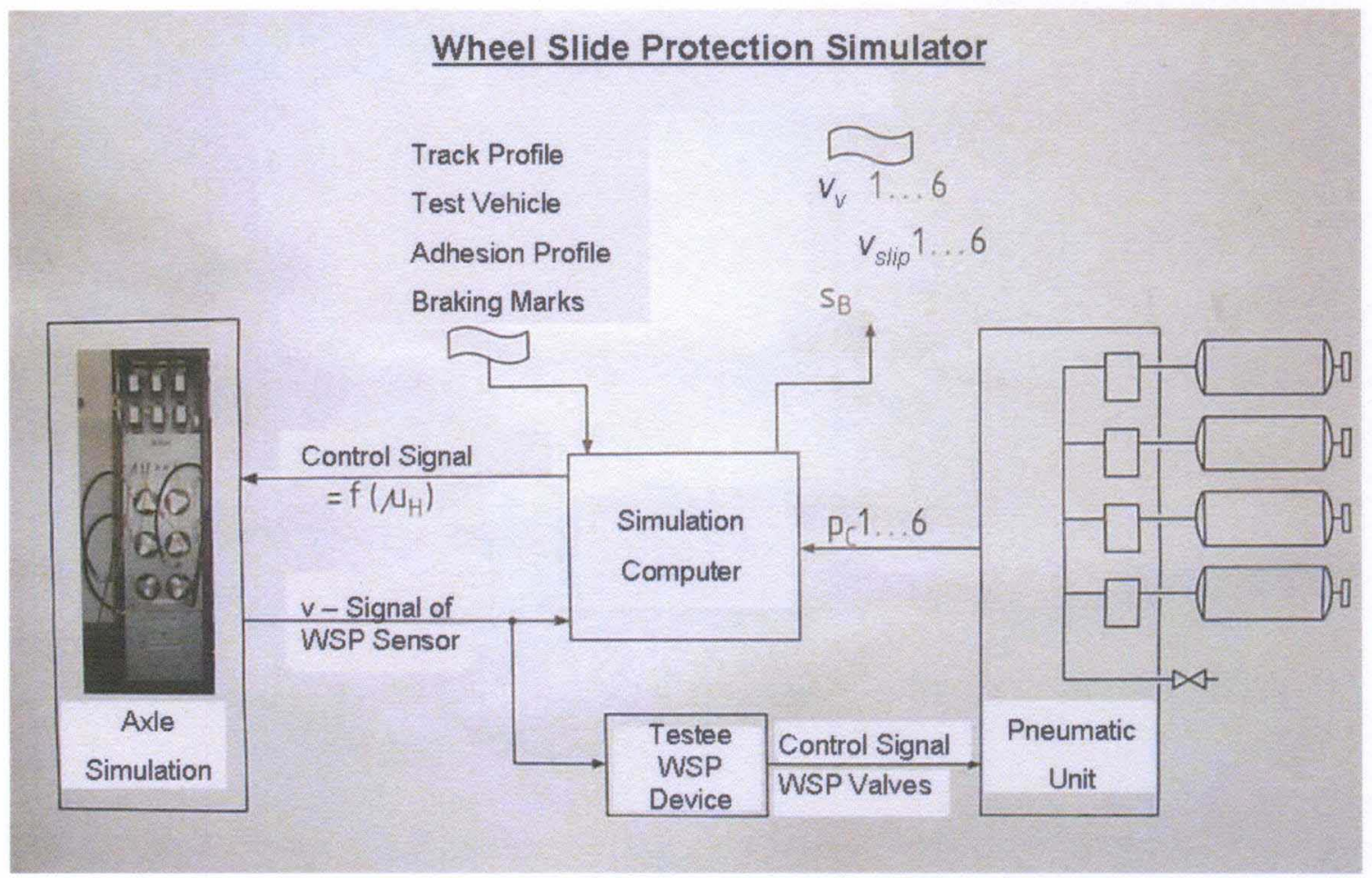

FIG. 4.1 Scheme of the Wheel Slide Protection Dynamometer. (DB Systemtechnik (2010))

The Simulation computer runs a program that includes the track profile as well as information to the test vehicle which shall be simulated. The test vehicle can be a locomotive, a rail car, a passenger coach, and whatever the tested WSP device is supposed to end up in. The program also provides an adhesion profile and the braking marks on the simulated track profile. When the program is loaded the simulation computer sends out a control signal to the axle simulation causing them to turn as if the vehicle would set itself in motion. It also causes them to slow down when the simulated 
brake mark is passed thereby simulating the braking process. From the turning axles are then the v-signals sent back by being read by the WSP sensors which are placed on each axle. The v-signal is then read by the simulation computer and the tested WSP device. The WSP device reacts on deviations of the v-signal to the simulated velocity over ground which is also provided by the simulation computer. The WSP device's reaction is to control the WSP valves in the pneumatic unit. The WSP valves are either venting the fed air pressure or hold it. What condition is chosen depends on the wheel slip velocity which is also provided by the simulation computer. The air pressure of each brake cylinder is read and saved by the simulation computer too. Although this information has no effect on the WSP device it however is important for the simulation and its calculation in the background. The result of a test run will be a braking distance $s_{B}$ which will be saved with all the rest of the data. In addition to that the simulation computer has a display on which the development of all the signals can be pursued. These signals can be put in a printable data chart, once the saving of them is concluded.

\subsubsection{Axle Simulation Unit}

FIG. 4.2 is a picture of the Axle Simulation Unit. It is equipped with six motor units to simulate a maximum of six wheel sets. In this picture however only four wheel sets are simulated. Each wheel set is equipped with one capacitive WSP sensor. A pulse wheel is mounted to each wheel set. In this case the pulse wheel has 80 teeth hence giving 80 impulses per round. The impulses are captured by the WSP sensor which transmits them to the WSP device and the simulation computer. The wheel sets are also each mounted with a weight to approach the motor movement to the much more inert mass of a real wheel set. The motors are controlled by a frequency which is generated by the 4 quadrant 
servo controller units. They are placed in the top area of the motors. The signal to generate the frequency again is generated by the simulation computer.

The WSP sensors can vary depending on the WSP device to be tested. Also depending on the rail vehicle that is simulated are the pulse wheels exchangeable.

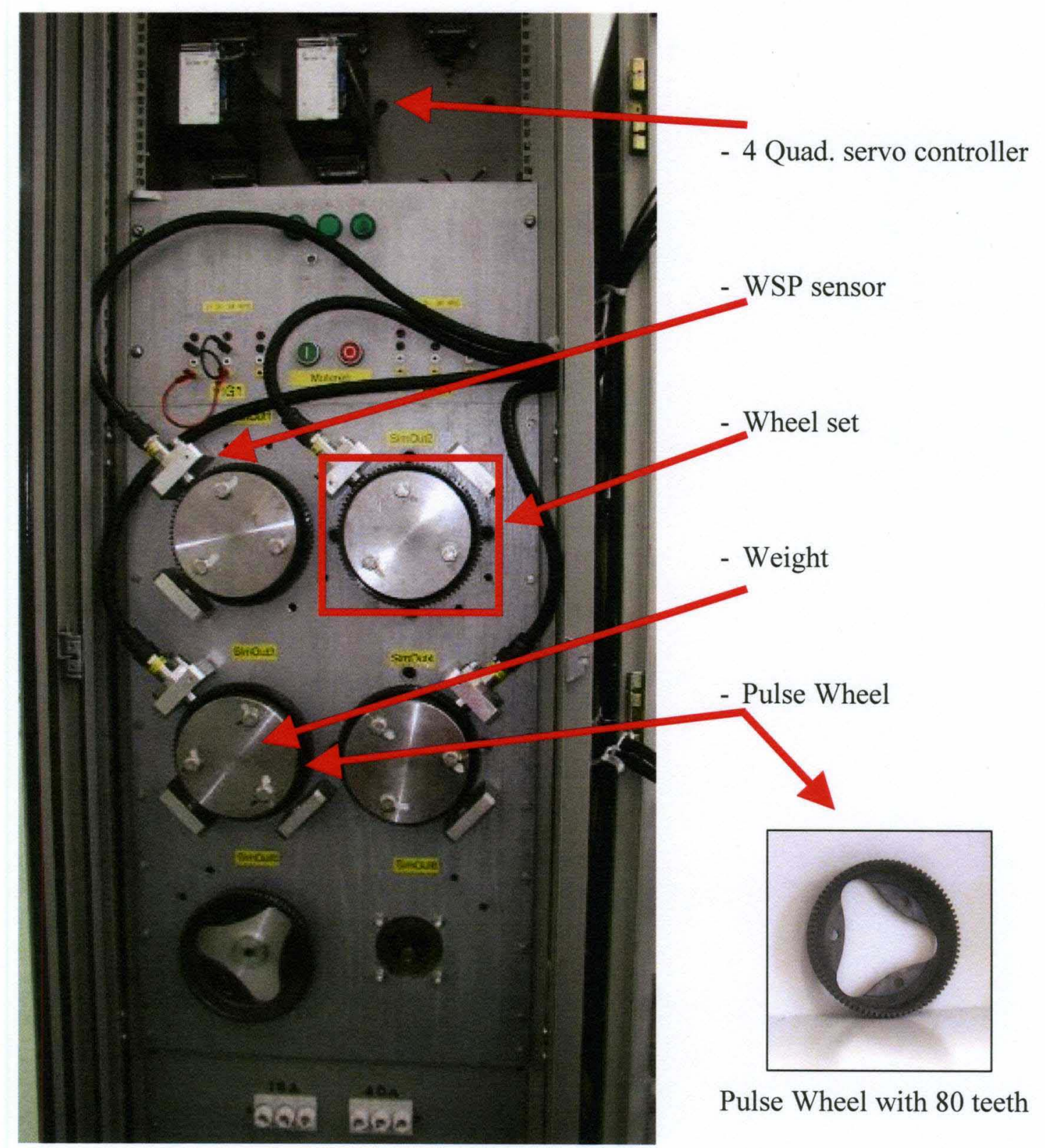

FIG. 4.2 Axle Simulation Unit of WSPD. (DB Systemtechnik (2010)) 
Today 80 teeth per round is still a common number. However the tendency is to measure more precisely through higher signal frequencies which then demands other pulse generating solutions such as incremental pulse generators. Those can deliver more than 1000 impulses per round.

\subsubsection{Pneumatic Brake Simulation Unit}

The Pneumatic Brake Simulation Unit is where the signals of brake operations are produced. This unit consist of WSP valves and sensors as well as air pressure tanks to simulate the brake cylinders and the air reservoirs.

The WSP valves are shown in FIG. 4.3. They are attached to the air pressure feed and convey the pressure further to the brake cylinder tanks. Built into each of the valves is also a WSP valve pressure sensor. This is not in every configuration the case, but the one in the picture is an example where it is. The valves receive their control signals from the WSP device which tells them to either vent the pressure of the cylinder attached or to hold it. Not at last for security reasons the inactive position of the WSP valves is "flow". That way the pressuring of the brake cylinders is secured also if the WSP device is somehow inactive or faulty. The three possible positions a WSP valve can take therefore are E for exhaling the air, in earlier context called venting; 0 for flow or filling the cylinders with air pressure, if provided; and $\mathrm{H}$ for holding the air pressure in the cylinder the way it is at the moment when this signal is set. The WSP valves may be on flow all the time the brakes are not active. However that doesn't imply pressurized brakes. To pressurize the brakes and thereby tighten them it is need for the pre-pressure valve $p C V$ to provide air pressure. That only happens when a braking signal is set. 


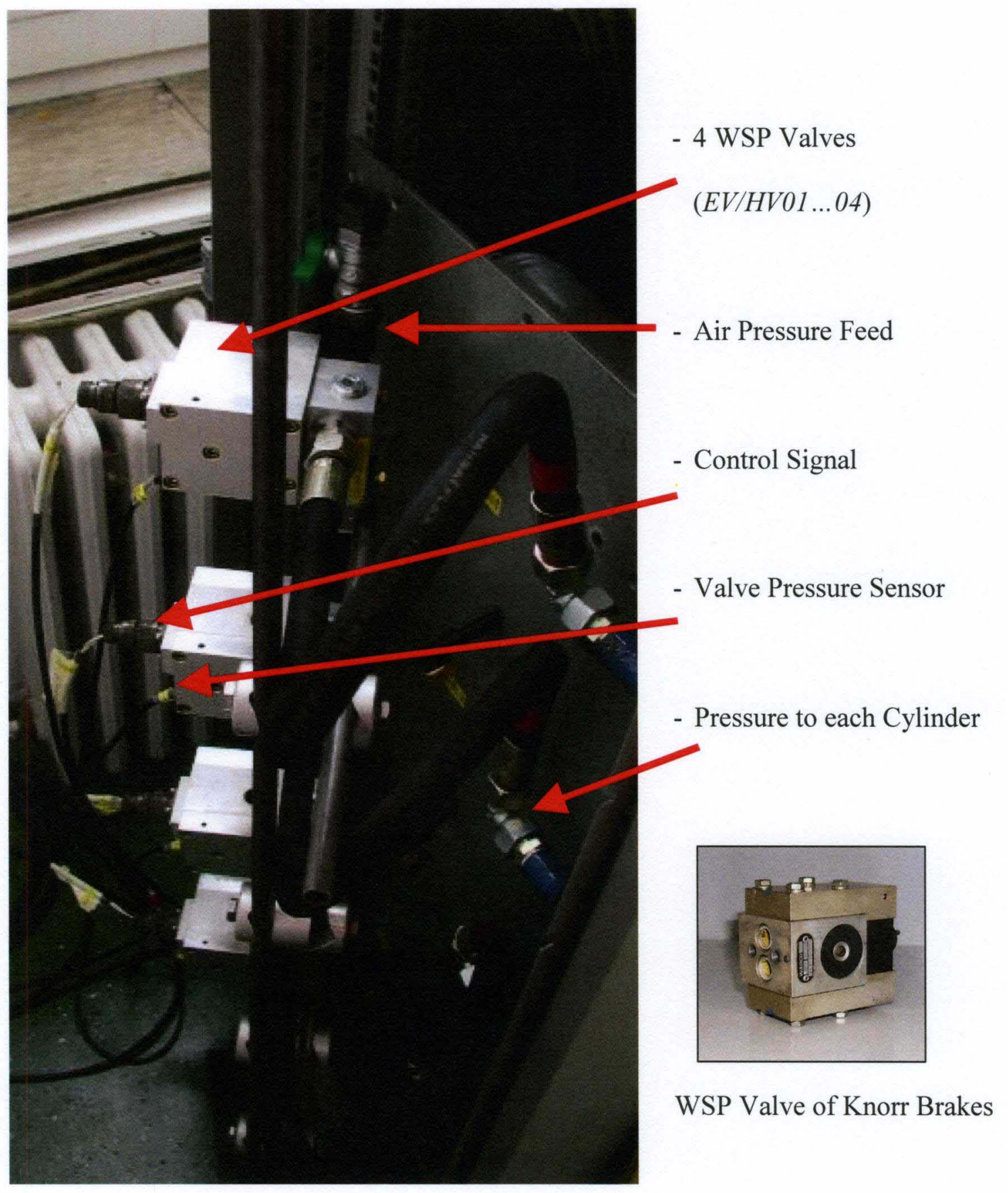

FIG. 4.3 WSP Valve Unit (EV/HV01...04). (DB Systemtechnik (2010))

The exhaust opening of the valves is built in the lower side underneath the valves. That is also for security reasons, in case a person is close to the valves when they vent the cylinder pressure. In any case a person would not willingly remain close to the valves for 
a long time when they vent. The noise it makes, though depending on the valve construction itself, is easily close to $120 \mathrm{~dB}$. In the picture of the WSP valve of Knorr Brakes the lower side of the valve is shown. The black circle is a rubber joint on top of the venting exit of the valve. The joint keeps dust and other impurities from entering the inner of the valve. The two other holes on the left side of the Knorr valve are entrance of the fed pressure and exit to the brake cylinder.

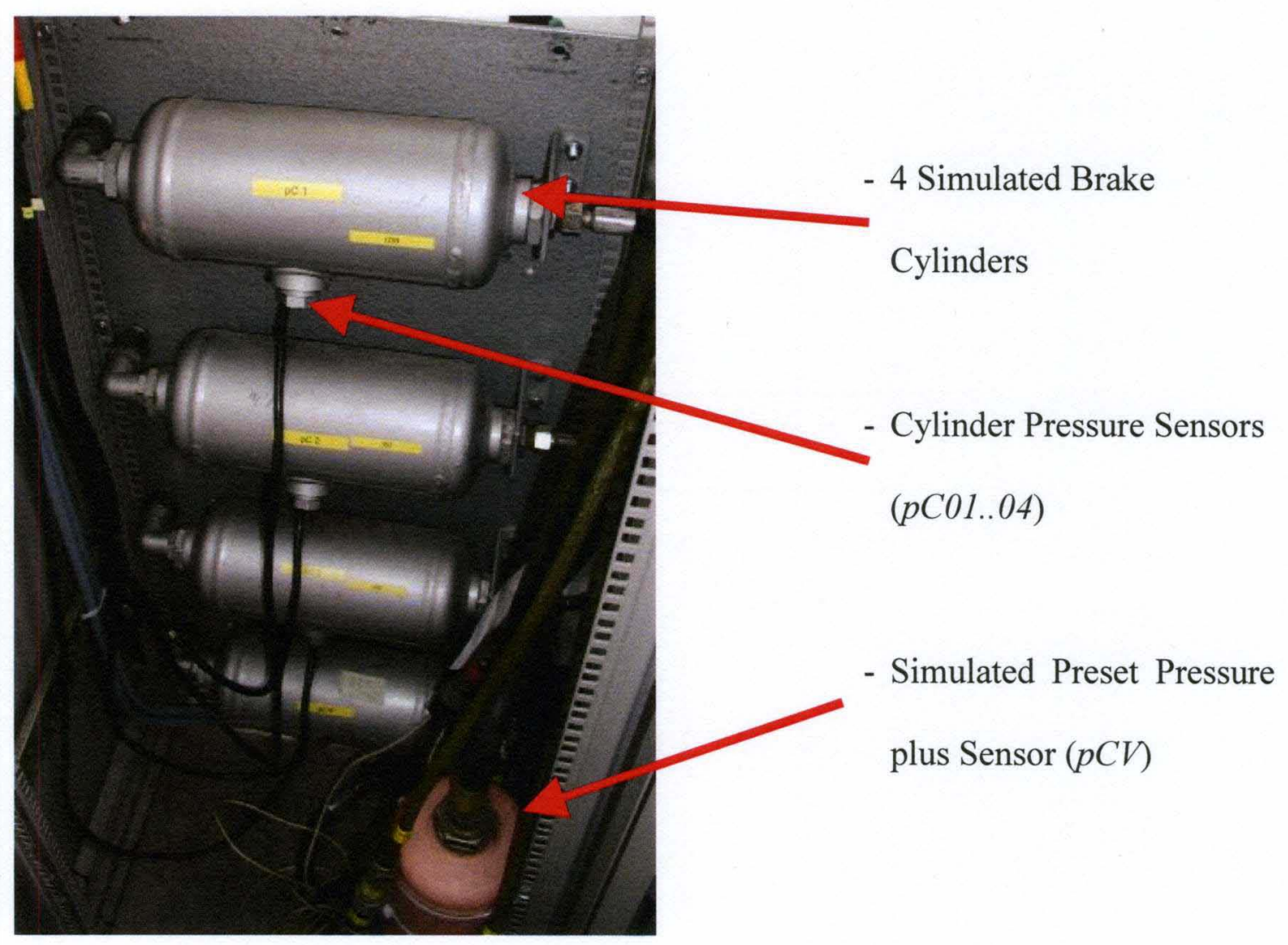

FIG. 4.4 Brake Cylinder Unit (pC01...04). (DB Systemtechnik (2010))

In FIG. 4.4 the four brake cylinders are shown. The four tanks are a simulation of the cylinder capacity. In this case the capacity of $p C 01 \ldots 04$ is 3 liters each. Attached to each cylinder is also a pressure sensor which provides the cylinder pressure $p C n$. 
The light red tank in the lower right corner of the picture is the simulatd preset pressure $p C V$ which is only under pressure when a braking signal is provided. Also here a pressure sensor generates a signal $p C V$ which is forwarded to the Simulation Computer this time. In case of braking the $p C V$ sends the air pressure to the four WSP valves which then distribute the pressure to the cylinders attached.

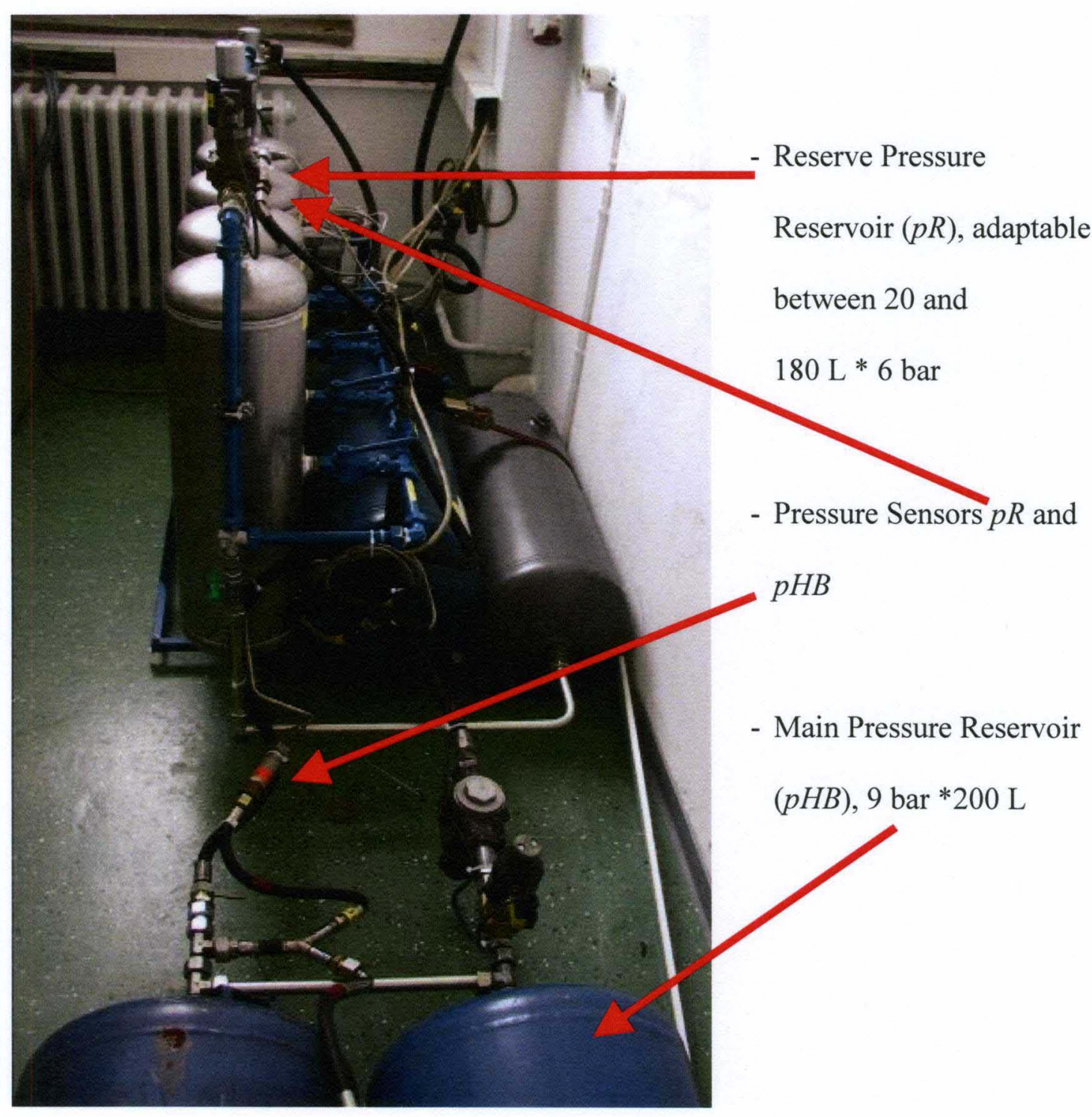

FIG. 4.5 Pressure Reservoir Unit (pR and pHB). (DB Systemtechnik (2010)) 
In the picture above, FIG. 4.5, the constellation of the pressure reservoirs is shown. There is the Main Pressure Reservoir in the lower part of the display and the Reserve Pressure Reservoir in the upper part. The Main Pressure Reservoir has the size of 200 liters and is filled with 9 bar of air pressure in the beginning of each braking. It also has a sensor attached to it that provides the pressure $p H B$ of the reservoir to the simulation computer. Normally the $p H B$ is filled by a compressor on the locomotive or rail car respectively. In the laboratory the needed air is compressed by an engine in the facility.

The Reserve Pressure $p R$ is filled by the $p H B$ reservoir. It provides the pressure feed for the $p C V$. The $p R$ consists of six pressure tanks. Four of them have a 20 liter volume and two are the size of 50 liters. For simulation flexibility this reservoir can be reduced in its volume by adding or shutting tanks off the circuit.. The minimal volume of $p R$ is therefore 20 liters and the maximum is 180 liters. Any volume in between that and in steps of 10 liters can thus be simulated. The $p R$ is 6 bar and is also captured by a sensor to forward it via the simulation computer.

\subsubsection{Signal Processing Units}

Every pressure, axle velocity, $E$ and $H$ position of the WSP valves, and all the other signals are fed into the Signal Processing Units. There the signals are filtered, transformed, or simply forwarded to the simulation computer. The most important of the signal processing units are all stacked in one 19" rack which is shown in FIG. 4.6.

The signal of the axle velocity $v 01 \ldots 04$ is provided by the WSP sensors which are next to each axle. It is frequency between 0 and $8 \mathrm{kHz}$, depending on the speed each axle is turning with. The signal is directly forwarded to the WSP device to be processed there. Parallel to that the signal is processed in the computing unit. Before it enters the $\mathrm{CU}$ it 
runs through a frequency voltage converter to become a voltage signal. After that it goes through a low pass filter of $30 \mathrm{mHz}$. Also the Reference Velocity $v$ Ref, which is always

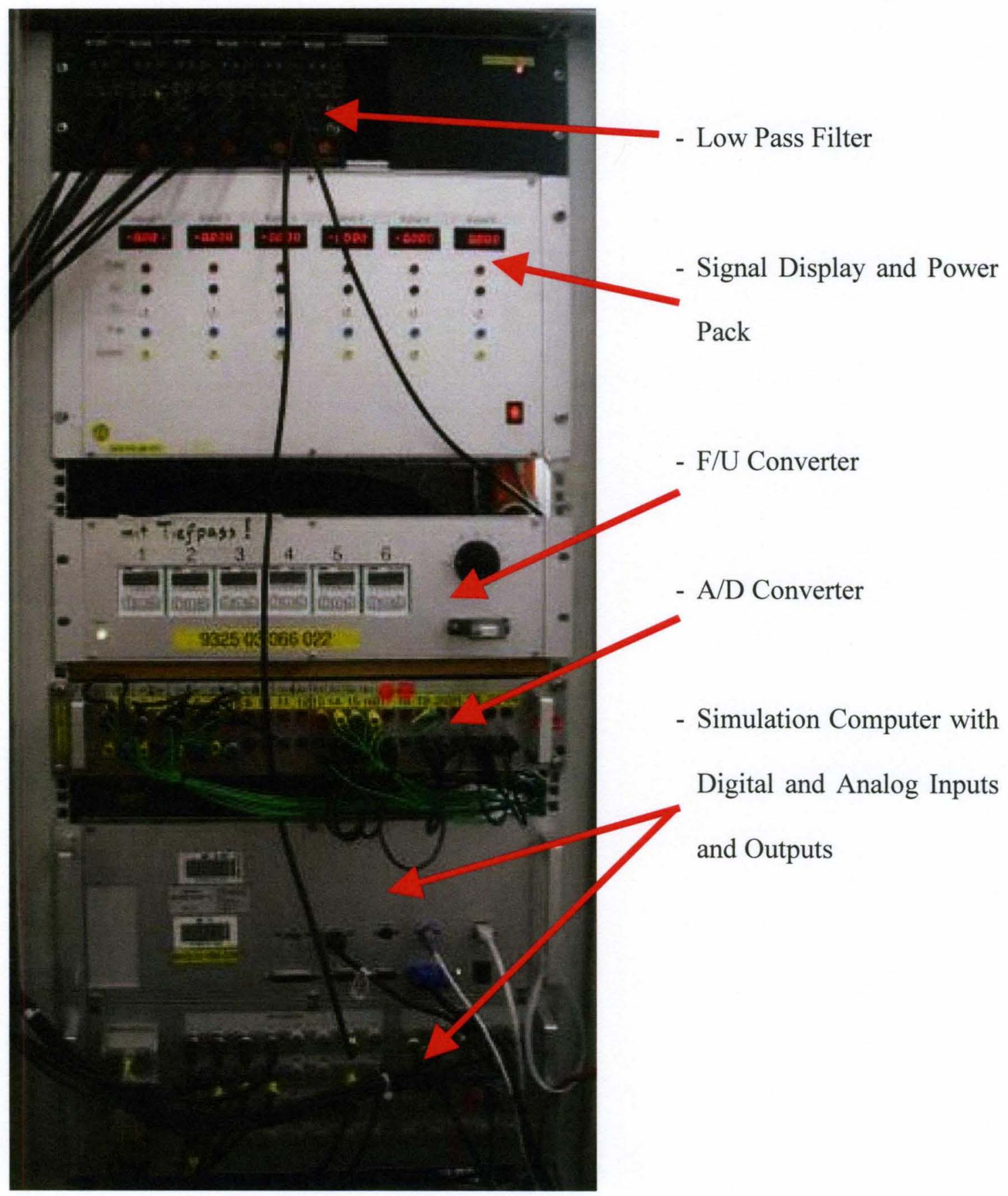

FIG. 4.6 Signal Processing Units in Rack. (DB Systemtechnik (2010)) 
calculated of the original axle velocities v01...04 and provided by the WSP device, runs through a low pass filter before it enters the CU. Here the filter is $2 \mathrm{mHz}$. The voltage signals then enter the simulation computer as analog inputs.

Voltage signals which are carrying only the information if a device is on or of or if a signal such as WSP on/off is set, are processed by the analog digital converter to a digital $1 / 0$ signal. The digital signals are the read into the simulation computer via the digital inputs.

\subsubsection{Computing Unit}

The heart of the WSP Dynamometer is its Simulation Computer. On this unit is the program which runs the simulation algorithm and all the signals are merging here.

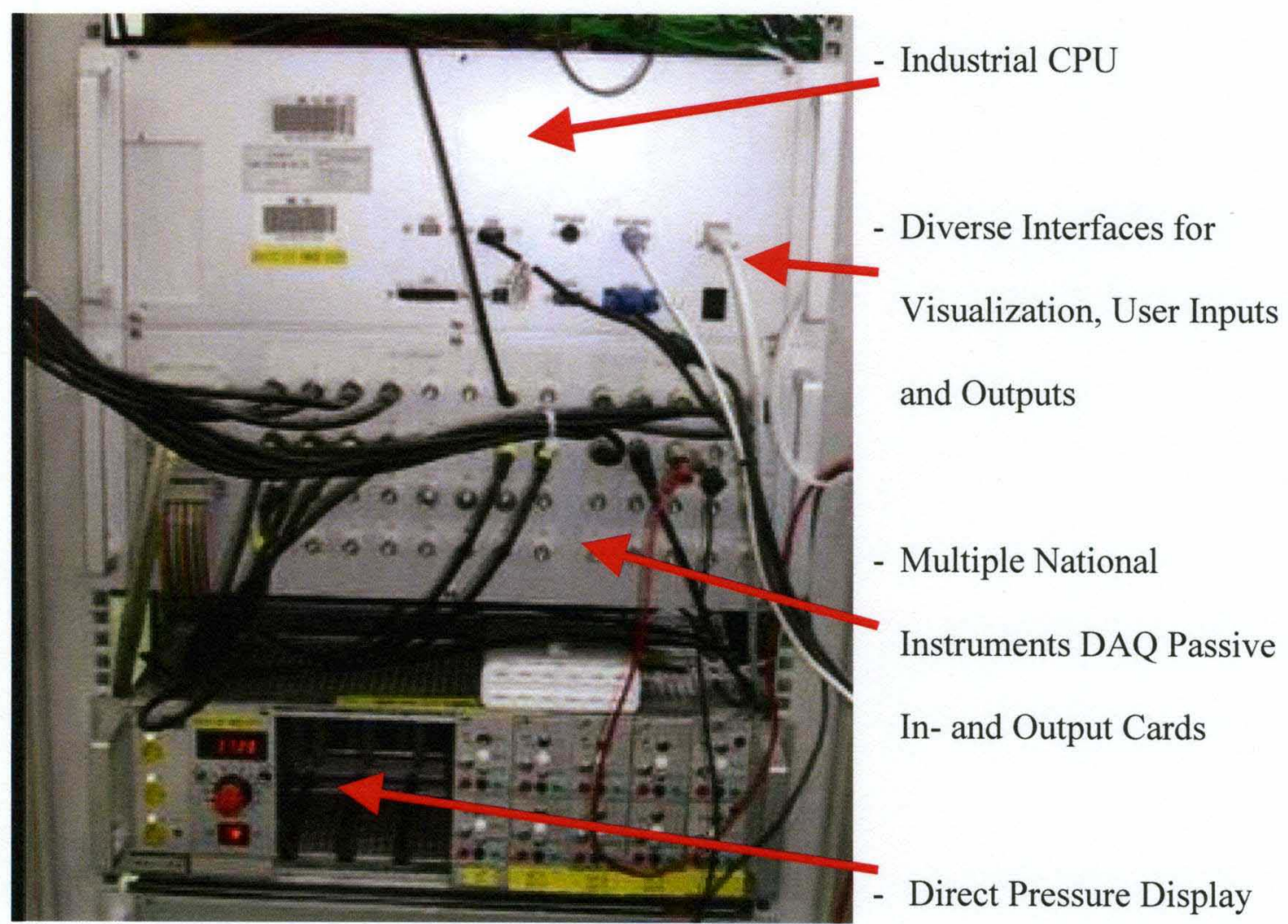

FIG. 4.7 Simulation Computing Unit. (DB Systemtechnik (2010)) 
In FIG. 4.7 is a picture of the Computing Unit with its interfaces. The unit consists of an industrial CPU with the common interfaces of a personal computer such as mouse, keyboard, three screens, Ethernet, USB, RS232, and a parallel port. What makes the difference, are the numerous National Instruments DAQ signal processing cards for analog and digital in- and outputs. Supplementary to the computing unit is a direct pressure display. All the measured pressure signals pass through this display and can be verified before being processed. That can be very useful when searching to comprehend an unforeseen reaction in the simulation.

\subsubsection{Wheel Slide Protection Device}

Wheel Slide Protection Devices are also known as Anti-Skid Devices. That is just another name for the same thing. The WSP Device is the testee for which the WSP Dynamometer initially was build. Therefore is rank of importance should come right after the computing unit of the dynamometer.

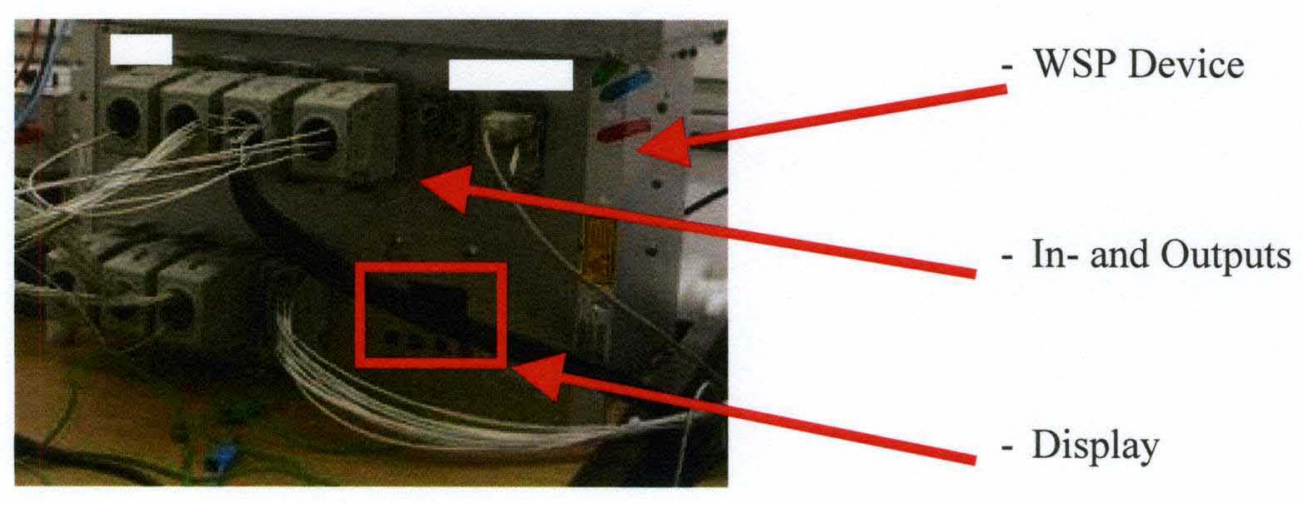

FIG. 4.8 Example of WSP Device. (DB Systemtechnik (2010))

The FIG. 4.8 shows an example of a WSP device that has been tested on the WSP Dynamometer. The manufacturer can not be named and neither can any detail of its performance during the test be stated. The WSP device has interfaces for in- and outputs 
of the various signals such as the frequencies of the wheel set velocities, pressure of the environment, pressure of each WSP valve, $E$ and $H$ signal for each WSP valve, braking mark, $v$ Ref and others. It also has a display for maintenance. Here standardized codes will give information about the current situation of the WSP device such as immediate failures or saved failures since the last memory read out. The WSP device will be built into a rail vehicle just the way it is shown on the picture, except the signal lines will all be electromagnetically shielded.

\subsection{The WSPD Algorithm}

The Wheel Slide Protection Dynamometer Algorithm (WSPD Algorithm) is based on the Program DIAdem ${ }^{\circledR}$ which again runs the algorithm code based on Visual Basic ${ }^{\circledR}$.

DIAdem is an analyzing software of the software manufacturer National Instruments. This software is a specialized tool for signal analysis in the automotive industry's research and development. In the case of the WSPD it runs on the operating system MS Windows ${ }^{\circledR}$. The example in FIG. 4.9 gives a brief impression on how the WSPD algorithm is implemented in the Visual Basic programming language. The operations of the algorithm are based on multiple functions that are compiled in separate subsequences. This allows to adapt the algorithm through a top down approach to the special needs of each new WSP device to be tested. The operations stay the same while the functions can be modified to fit the needs to each individual case.

The Visual Basic code however operates in combination with a function plan which is loaded and run in each test. The function plan surface in DIAdem is called DAC. Which DAC and which operation and which function will be loaded and compiled in each specific test run will be read out of a table which is a MS Excel ${ }^{\circledR}$ file. 


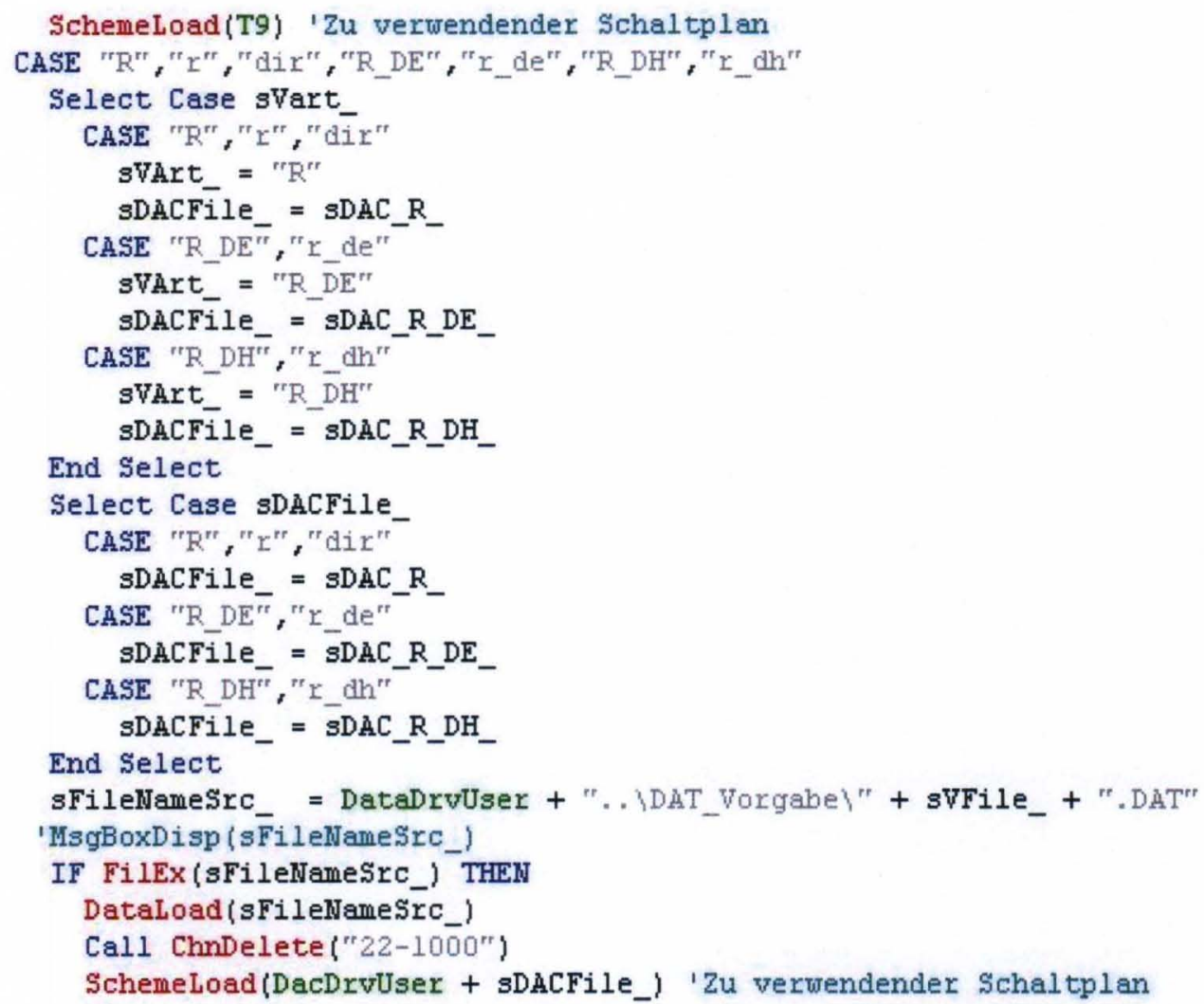

FIG. 4.9 Example of Simulation Code. (DB Systemtechnik (2010))

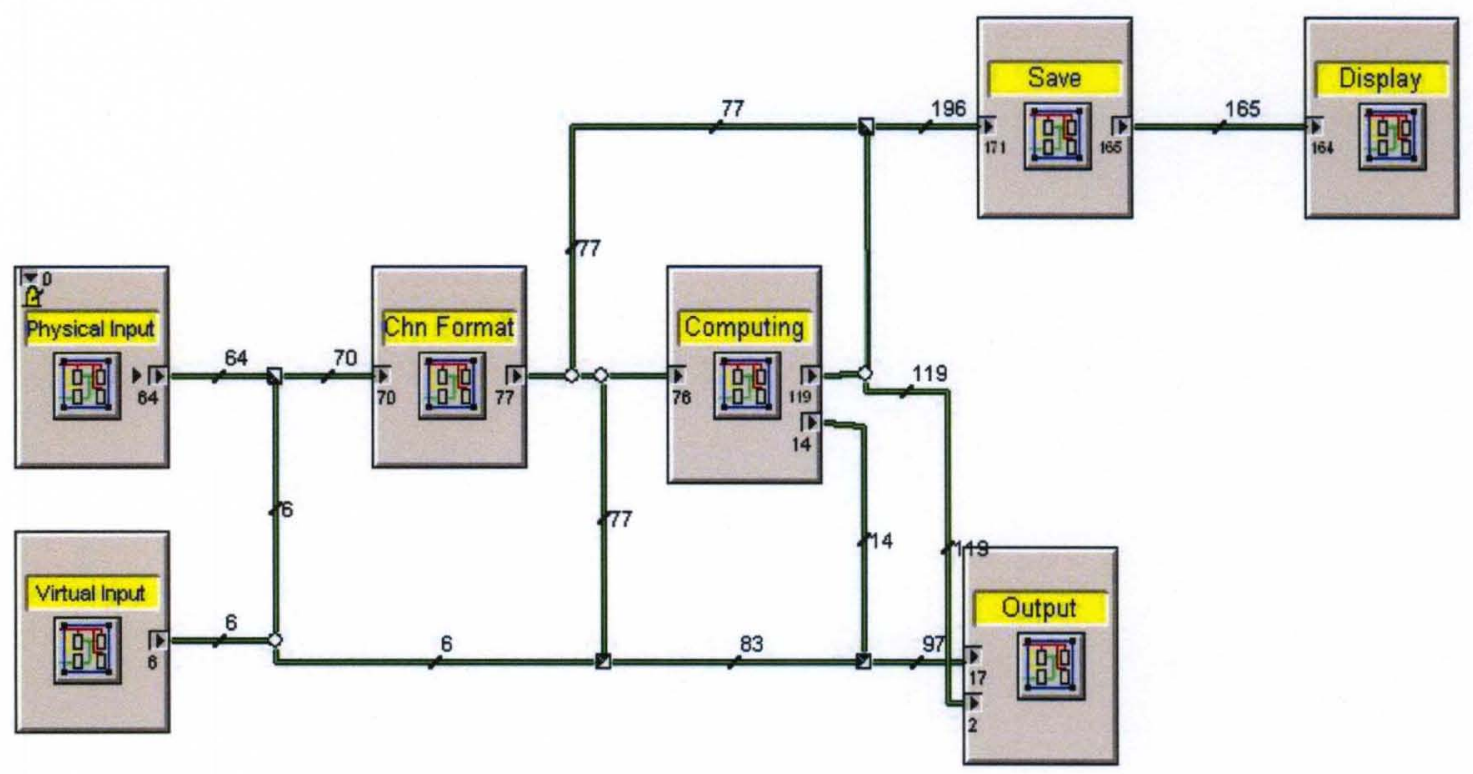

FIG. 4.10 Simulation Algorithm Breakdown Structure. (DB Systemtechnik (2010)) 
The Excel file however is started by the DIAdem software again. In FIG. 4.11 the DIAdem program cycle operations are visualized.

\section{DIAdem Program Cycle Operations}

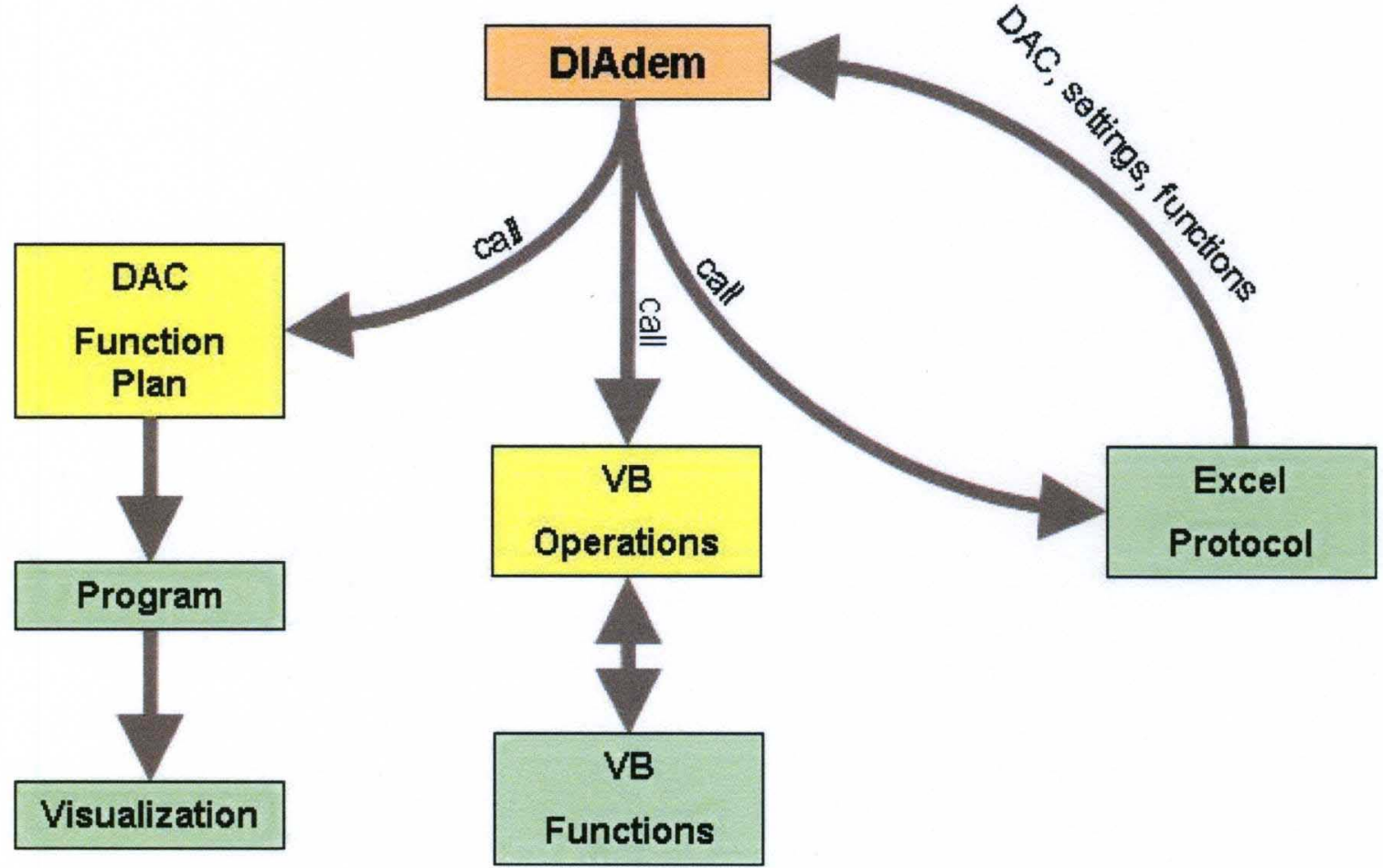

FIG. 4.11 Visualization of DIAdem Program Cycle Operations.

\subsubsection{Physical Inputs}

The Physical Inputs of the WSPD algorithm are divided into Analog Inputs and Digital inputs. The following are theAnalog Inputs:

- $\quad$ measured wheel set velocity frequencies $f 01 \ldots 04$

- $\quad$ reference velocity $v$ Ref provided by WSP device

- $\quad$ measured pressures of each brake cylinder $p C 01 \ldots 04$

- measured preset pressure $p C V$ 
- measured reserve pressure $p R$

- measured main pressure $p H B$

The following are the Digital Inputs:

- $\quad$ E/H signal, provided by WSP device, E/H01 ...04

- Lower $45 \mathrm{~km} / \mathrm{h}, v 45$, on / off

- Lower $5 \mathrm{~km} / \mathrm{h}, v 05$, on / off

- Sanding, provided by WSP device, Sand, on / off

- Error, provided by WSP device, Fehler, on / off

- WSP active, provided by WSP device, BSG_aktiv, on / off

- Wheel set alignment, provided by WSP device, Radabgl, on / off

\subsubsection{Virtual Inputs}

The Virtual Inputs are part of the DAC program. The provide variables which are not read by any other interface but still needed to ensure the function of the simulation. The Virtual Inputs are:

- Emergency shutdown

- $\mathrm{Hz}$ per $\mathrm{km} / \mathrm{h}$

- Brake leverage ration $\mathrm{i}=\mathrm{x}$ 


\subsubsection{Computing}

The Computing Function Block is the heart of the algorithm. It consist of numerous other function blocks which in the end form the major operations of the algorithm. The most important function blocks are:

- Wheel-Rail Parameters

- Pneumatic Brake Parameters

- Magnetic-Rail Brake Parameters

- Train Resistance Forces

- Simulated Traction Vehicle Parameters

- Preset Pressure Parameters

- Vehicle Forces

- Wheel Set Forces

- Friction Energy Parameters

- Digital Values

- Lecture of Settings Files

- Acceleration and wheel slip parameters

\subsubsection{Outputs}

The Outputs are also divided into Analog Outputs and Digital outputs. The Digital Outputs are:

- refill of reserve pressure reservoir $p R$ on / off

- refill of main pressure reservoir $p H B$ on / off

- Magnetic rail brake $M g$ on / off

- Braking Brems on / off 
- Traction Fahr on / off

The Analog Outputs are:

- $\quad$ control of simulated axle velocities $f 01 \ldots 04$

- $\quad$ preset pressure control $p C V$

- $\quad$ simulated velocity over ground $v_{v}$

\subsubsection{Saves and Display}

Every single signal is saved. That is a number of approximately 160 different signals, depending on the type of simulated vehicle. The most important signals for the simulation are displayed simultaneously to the simulation. The signals are the pressure of each brake cylinder as well as reserve and main pressure, the velocity of each wheel set as well as velocity over ground and reference velocity, and the most important digital signals.

Since the tests can sometimes be done manually and sometimes automatically, there also is a Manual Display and a Automatic Control Display.

The Manual Display is shown in FIG. 4.12. It displays the most important variables $v, a$, $p, v_{s}$ and equally the important digital signals. All the signals here can be manipulated manually. That is usually done when the basic functions of a WSP device are tested.

The Automatic Control Display, shown in FIG. 4.13, built similar to the Manual Display. In this display only the Emergency Shutdown can be manipulated manually the rest is a display of the most important signals such as measured pressures, velocities, digital signals, and simulation values such as traction force and others. These signals are shown for visualization reasons only and can not be manipulated during an automatic test run. 

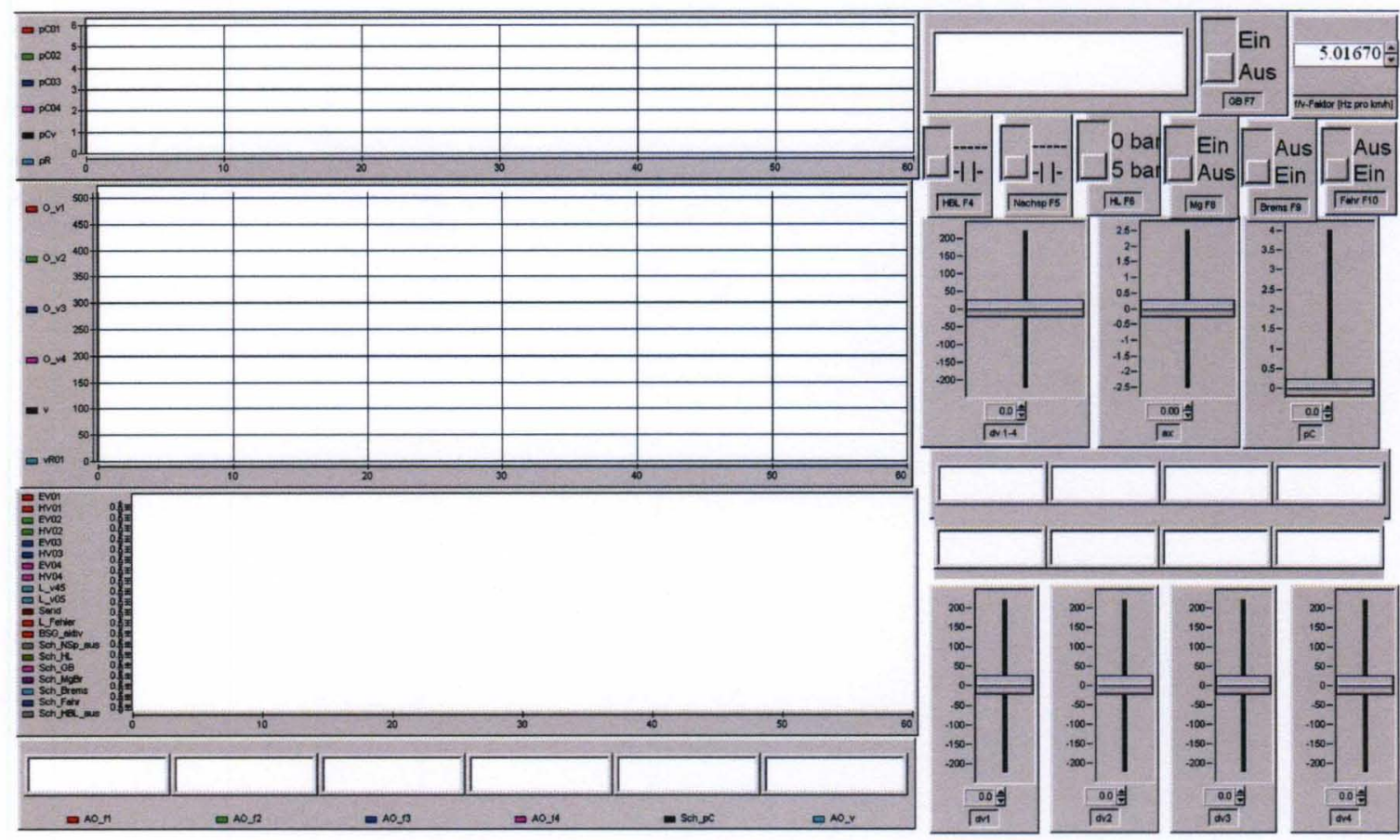

FIG. 4.12 Manual Control Display. (DB Systemtechnik (2010))
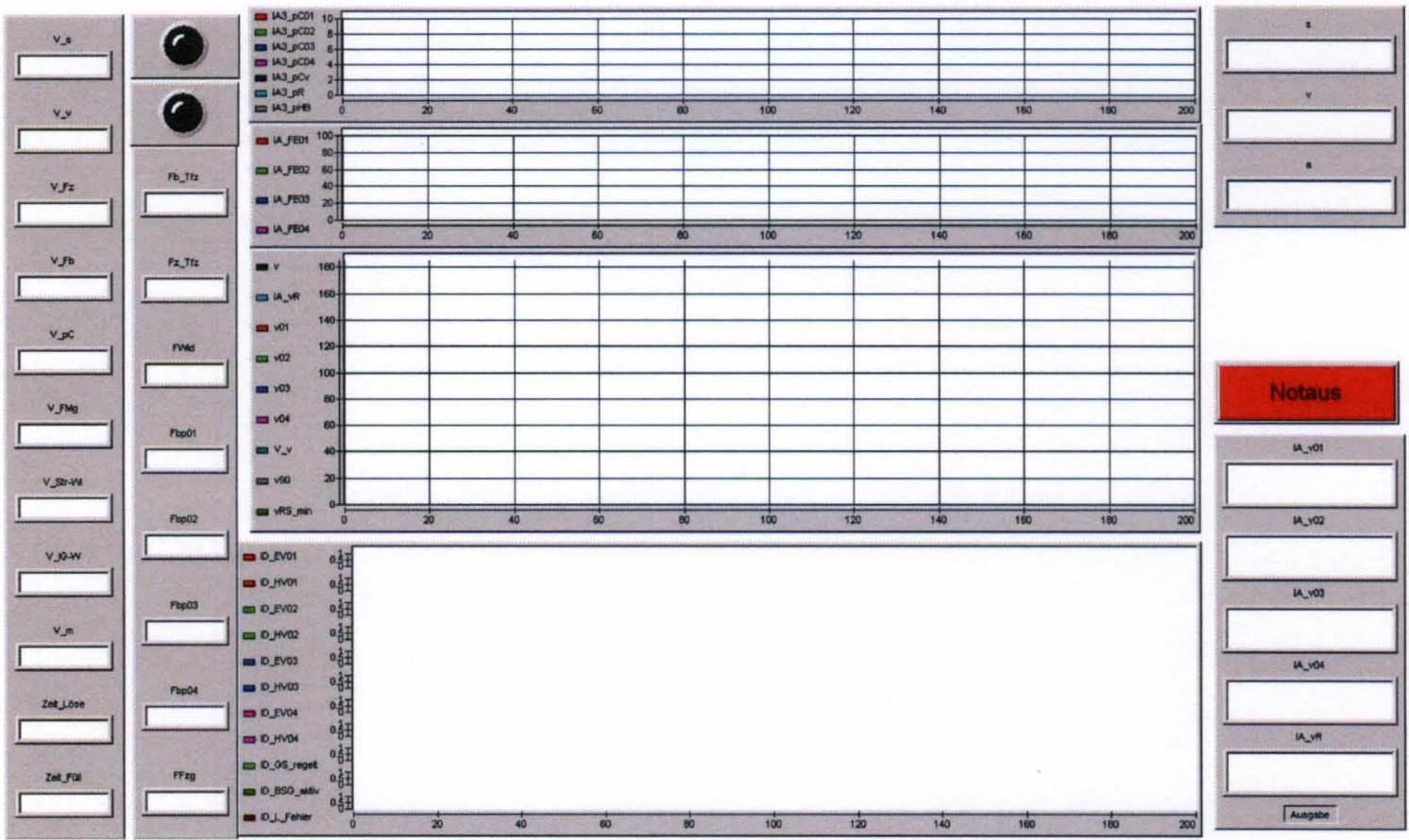

FIG. 4.13 Automatic Control Display. (DB Systemtechnik (2010)) 


\subsection{Data Charts}

The Data Charts provide a summary of each test run. They give a display of the simulated course beginning at the start of traction until end of braking, or stop of movement. Again they show the most important signals over the full test run period. But they are additionally displaying characteristic results such as braking distance, velocitiy at braking point, average deceleration during braking, maximum wheel slip per wheel set, and the average wheel slip over braking per wheel set over braking distance. An example of such a Data Chart is provided in FIG. 4.14 below.

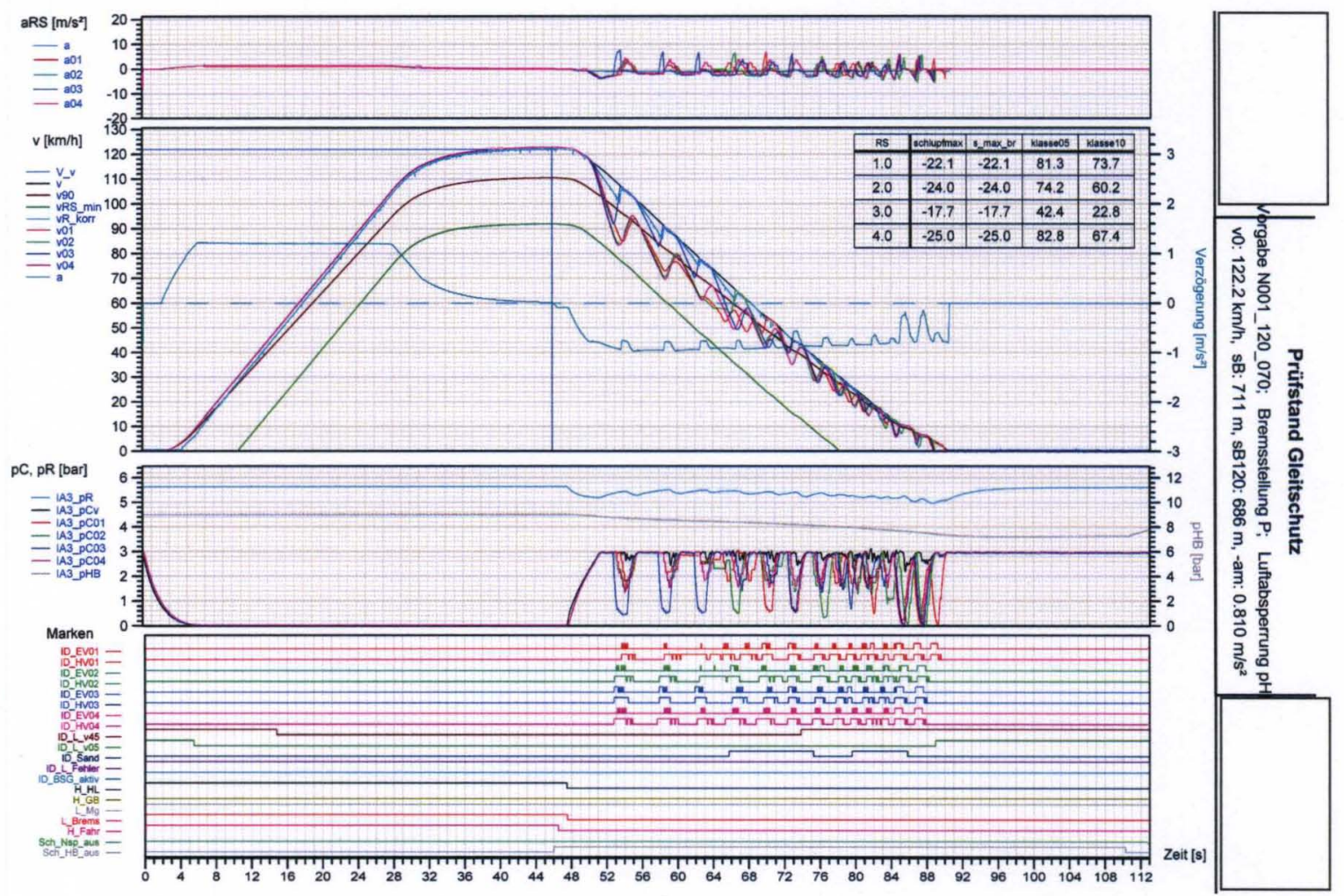

FIG. 4.14 Data Chart of a WSP Braking. (DB Systemtechnik (2010)) 


\section{AREAS FOR IMPROVEMENT OF THE WSPD}

The Wheel Slide Protection Dynamometer offers a good hand full of possible optimizations that could be implemented. However only one will be matter to a further investigation within this document. The report RP2 of the UIC task group B164 provides several lead to an optimized exploitation of the available adhesion during the braking process. The most remarkable improvement areas are those below:

- Adhesion curves - implementation of wheel slip dependent adhesion

- Conditioning of the adhesion coefficient for the pursuing wheel sets by the wheel sets which are running first

- Forces of Train Resistance, especially aerodynamics and friction

- Vehicle Pitching due to the braking deceleration

Furthermore the air consumption is a value which requires more precision in its measurement and the motor frequency could be simulated with the aid of a UF-converter, to reduce electro-magnetic noise problems and motor vibrations in the simulation.

\subsection{Choice of improvement}

The improvement of the Adhesion Curves seems to be of highest rank when it comes to the choice of optimization. A wheel slip dependent adhesion value has been proved in many researches and must therefore imperatively be implemented in the WSPD algorithm. To maintain state of the art technology. Not only has the WSPD be up to date 
compared to other dynamometers on the market but also has it to respond to the technology on which the recent WSP devices base their calculations.

The new WSP devices all search in their algorithm the adhesion maximum during the braking process. The is not at least due to the premise of more effective braking and short braking distances even when the adhesion is low. 


\section{IMPROVEMENT OF ADHESION CURVES}

Although the UIC standard does not demand a simulation algorithm that includes wheel slip dependent adhesion it is long already part of the algorithms implemented in the recently developed WSP devices.

This chapter gives an overview of the development of the new Adhesion Curves and how these will be implemented in the present WSPD algorithm. Afterwards the effect of the improvement is tested. The findings conclude the implementation.

\subsection{Development of optimization}

Before the implementation of wheel slip dependent adhesion curves in the algorithm the

TAB. 6.1 Non-Wheel Slip Velocity depending Adhesion Value

\begin{tabular}{|c|c|c|c|}
\hline$\mu / v_{s}[\mathrm{~km} / \mathrm{h}]$ & $\mu / v_{s}$ & \multicolumn{2}{|c|}{$\mu$ Character } \\
\hline Setting File & 0,05 & $\mu$ constant & low $\mu$ \\
\hline N001_050 & 0,06 & $\mu$ constant & low $\mu$ \\
\hline N001_060 & 0,07 & $\mu$ constant & low $\mu$ \\
\hline N001_070 & 0,08 & $\mu$ constant & low $\mu$ \\
\hline N001_080 & 0,20 & $\mu$ constant & normal / dry $\mu$ \\
\hline T001_200 & 0,02 & $\mu$ constant & extremely low $\mu$ \\
\hline X001_020 & & & \\
\hline
\end{tabular}


adhesion value throughout the whole braking curse was constant. However the constant $\mu$ can have various values giving it a defined character in the magnitude that is demanded in the UIC standard for WSP tests. The TAB. 6.1 above shows the different setting files that have already been implemented and used in the WSPD algorithm.

In Order to the UIC standard (UIC 541-05 (2005)) the adhesion values during the test for low adhesion environment have to be between $\mu=0,08$ and $\mu=0,05$. The values extremely low adhesion tests may not exceed $\mu=0,03$.

In FIG. 6.1 are the non wheel slip depending adhesion curves visualized as they would appear in a chart. Since they have constant $\mu$ values they have the form of a horizontal line.

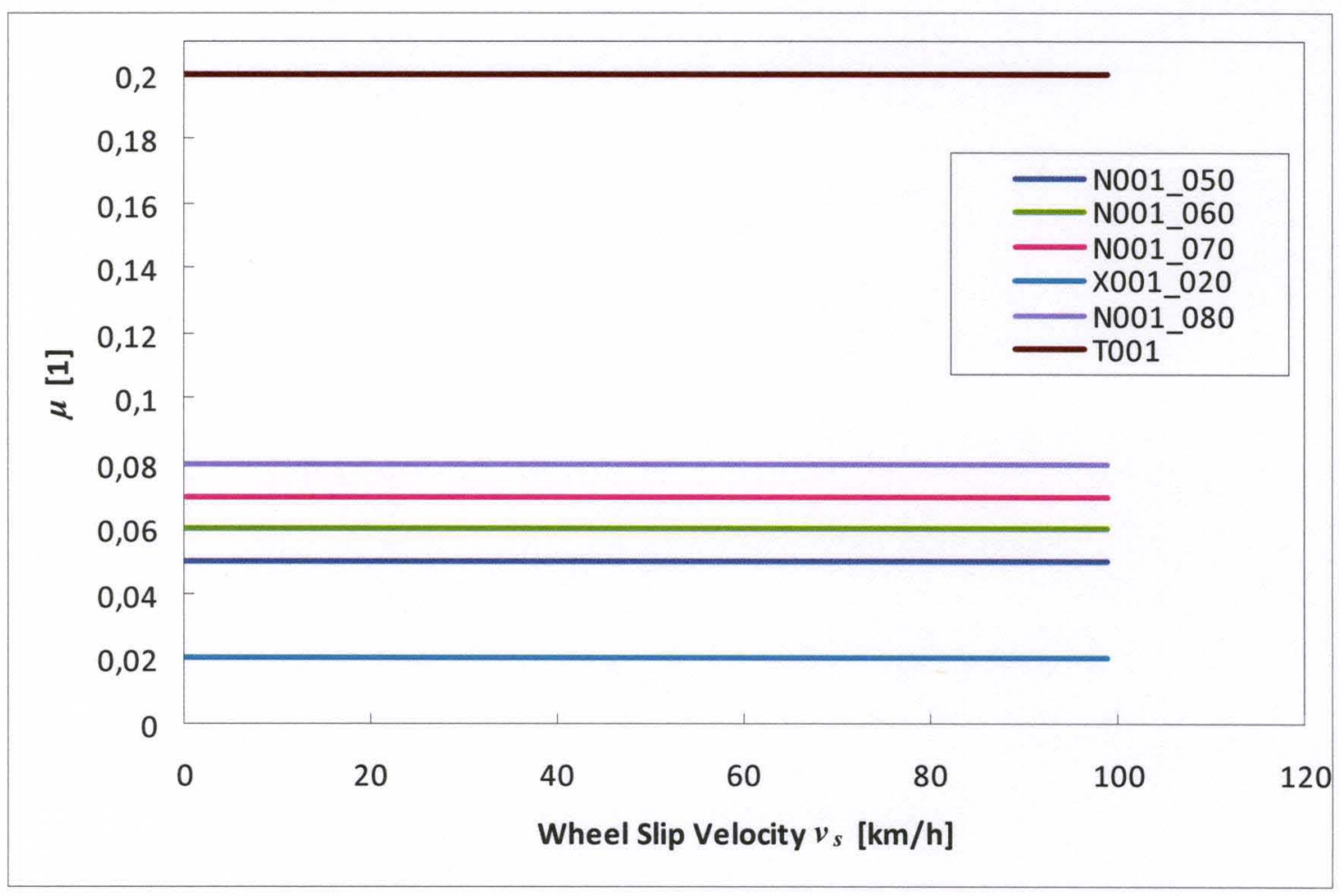

FIG. 6.1 Non Wheel Slip depending Adhesion Curves. (DB Systemtechnik (2010)) 
Based on the design that was explained in RP2 the devolution of the wheel slip dependent adhesion curves is a given. Since not all the three types (A. B and C) of curves can be provided in the same one. Given that at the present evolutionary stadium of the WSPD algorithm the programming of pure polynomial adhesion curves is not possible yet. The decision was made to implement a variation of an AB-Type curve with a fixed number of supporting points. The TAB.6.2 Wheel Slip Velocity dependent Adhesion ValueTAB. 6.2 below shows at which $v_{s}$ what kind of $\mu$ is expected.

TAB. 6.2 Wheel Slip Velocity dependent Adhesion Value

\begin{tabular}{|c|c|c|c|c|c|c|}
\hline${ }_{\text {Setting File }}^{\mu / v_{s}[\mathrm{~km} / \mathrm{h}]}$ & $\mu / v_{s} 00$ & $\mu / v_{s} 01$ & $\mu / v_{s} 02$ & $\mu / v_{s} 03$ & $\mu / v_{s} 05$ & $\mu / v_{s} 08$ \\
\hline N002_020 & 0,02 & 0,02 & 0,04 & 0,07 & 0,08 & 0,085 \\
\hline N003_020 & 0,02 & 0,02 & 0,05 & 0,06 & 0,08 & 0,09 \\
\hline X002_020 & 0,02 & 0,02 & 0,04 & 0,05 & 0,06 & 0,05 \\
\hline S002_020 & 0,02 & 0,02 & 0,04 & 0,05 & 0,06 & 0,07 \\
\hline${ }_{\text {Setting File }}^{\mu / v_{s}[\mathrm{~km} / \mathrm{h}]}$ & $\mu / v_{s} 12$ & $\mu / v_{s} 17$ & $\boldsymbol{\mu} / \boldsymbol{v}_{\boldsymbol{s}} 25$ & $\mu / v_{s} 35$ & $\mu / v_{s} 99$ & \\
\hline N002_020 & 0,088 & 0,09 & 0,085 & 0,07 & 0,06 & \\
\hline N003_020 & 0,1 & 0,109 & 0,121 & 0,132 & 0,18 & \\
\hline X002_020 & 0,04 & 0,03 & 0,02 & 0,02 & 0,02 & \\
\hline S002_020 & 0,075 & 0,078 & 0,075 & 0,06 & 0,05 & \\
\hline
\end{tabular}

Because the maxima of the curves is anticipated in below $v_{s}=20 \mathrm{~km} / \mathrm{h}$ the population of the supporting points is highest between $0 \mathrm{~km} / \mathrm{h}$ and there. 
The cutline to the different Setting Files given in the various figures, tables and charts is illustrated in TAB. 6.3. The three numbers after the root setting, ie. N002_020, is indicating the initial $\mu$ value when the braking sets in.

TAB. 6.3 Differences between the Setting Files

\begin{tabular}{|c|c|c|c|}
\hline Setting File & Initial $\mu$ & $\mu$ Character & Lubricious Agent \\
\hline N002_020 & 0,02 & low $\mu$ & $1 \%$ soap solution / $1 \%$ detergent solution \\
\hline N003_020 & 0,02 & low $\mu$ & Pure water \\
\hline $\mathrm{X} 002 \_020$ & 0,02 & ext. low $\mu$ & $100 \%$ soft soap / oil / water on paper \\
\hline S002_020 & 0,02 & low $\mu$ & $1 \%$ soap solution / $1 \%$ detergent solution \\
\hline
\end{tabular}

The various adhesion curves are again displayed in FIG. 6.2 below. The $\mu$ value is on the $\mathrm{y}$-axis over the $v_{s}$ value on the $\mathrm{x}$-axis. It is noticeable that the curve N003 unlike the other 


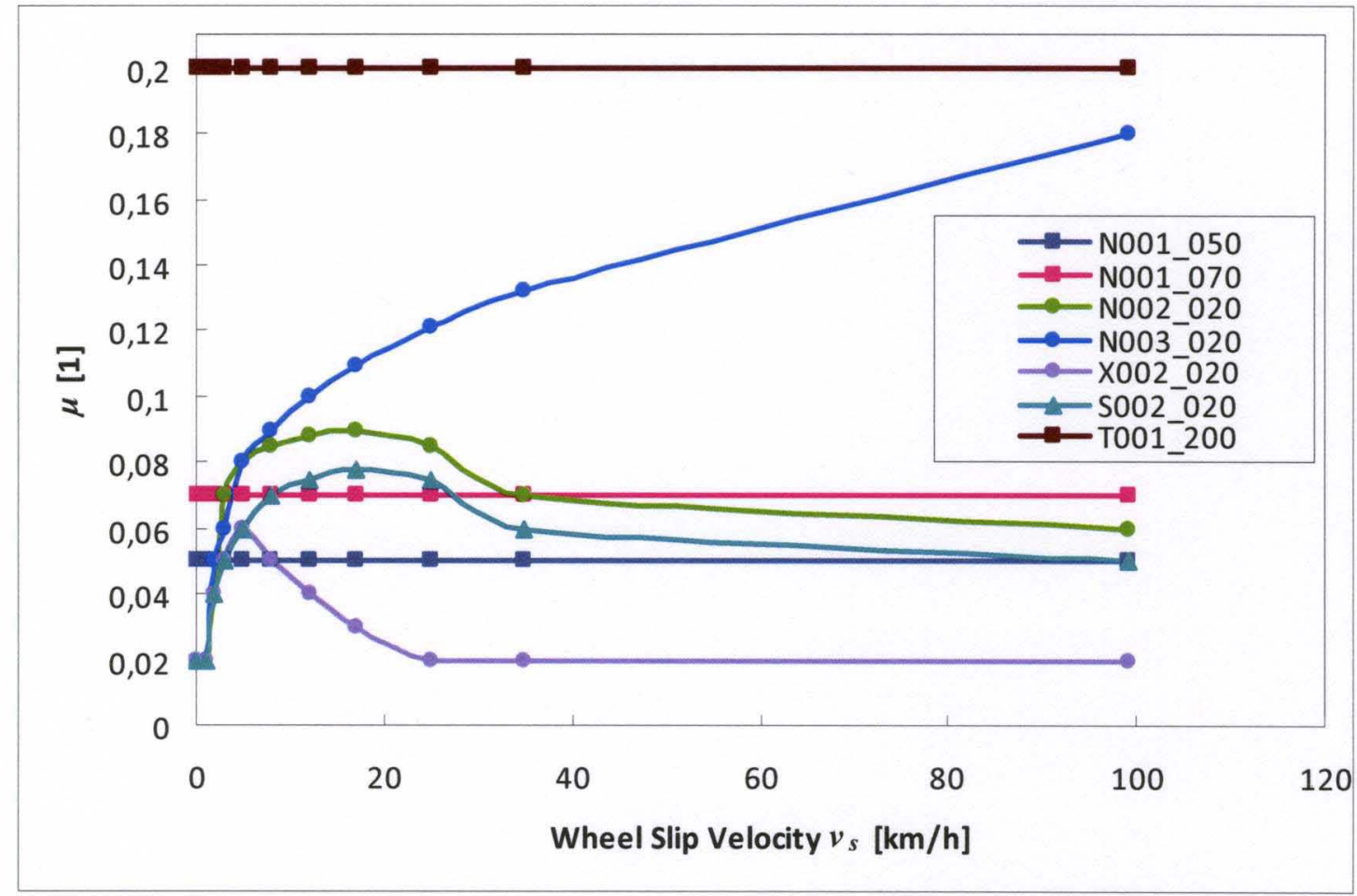

FIG. 6.2 Adhesion Curves depending on Wheel slip Velocity. (DB Systemtechnik (2010))

curves has no maximum. Reason for this is that the water curve will approach the dry curve with gaining wheel slip.

\subsection{Implementation of Algorithm}

For the implementation of the changes to the adhesion values a few steps have to be taken successively to finally achieve an algorithm that can process a $\mu\left(v_{s}\right)$ value. The first step lies in creating new virtual channels for each new $\mu$ value that was fixed previously.

Adding new channels can be done in the Computing function block. As shown in FIG. 6.3 the number of channels is listed in under the point "Kanal". There the new mue00, mue 01, mue $02, \ldots$ channels can be created. 

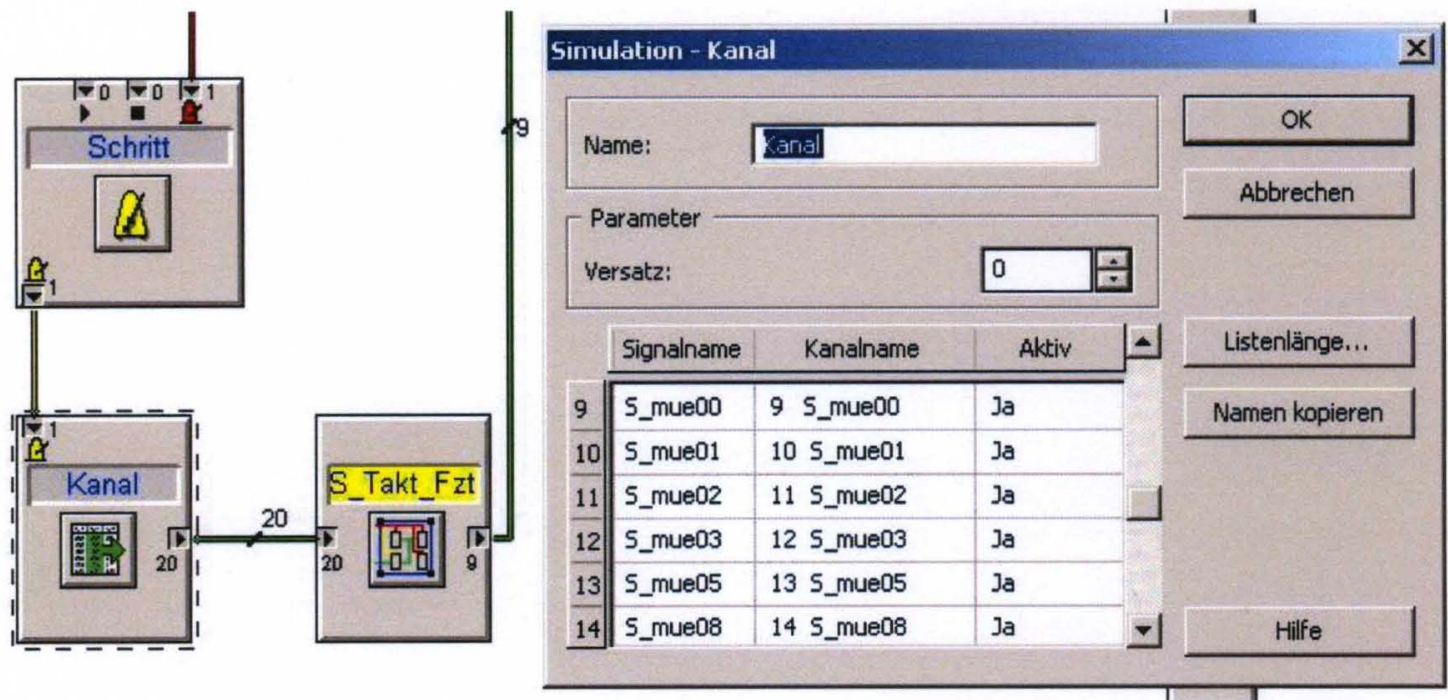

FIG. 6.3 Create new channels for mue00...99 in DAClComputing. (DB Systemtechnik (2010))

Once that is done the new channels also have to be called up in the Settings File which shall be used for the test runs. To get there either an exsisting Settings File can be copied and modified, or a completely new one can be built from scratch. The FIG. 6.4 shows the new channels how they are already entered in a N002_020 Settings File.

Once these steps are complete the new channels will be loaded at the next new start of the algorithm.

\begin{tabular}{|c|c|c|c|c|c|c|c|}
\hline IG-W & S_mue00 & S_mue01 & S_mue02 & S_mue03 & S_mue05 & S_mue08 & S_ \\
\hline & 9 & 10 & 11 & 12 & 13 & 14 & 15 \\
\hline singele... & eingele... & eingele... & ㅁ. eingele... & eingele... & ㅁ. eingele... & ㅁ. eingele... & प: \\
\hline \multirow[t]{3}{*}{ ischena... } & aus Zwischena... & aus $Z$ wischena... & aus Zwischena... & aus $Z$ wischena... & aus Z wischena... & aus Zwischena... & $\operatorname{aus} \mathrm{Zw}$ \\
\hline & & & & & & & \\
\hline & 4 & 4 & 4 & 4 & 4 & 4 & 4 \\
\hline$\overline{10}$ & 0.20000 & 0.20000 & 0.20000 & 0.20000 & 0.20000 & 0.20000 & $\overline{0.200 C}$ \\
\hline 10 & 0.20000 & 0.20000 & 0.20000 & 0.20000 & 0.20000 & 0.20000 & $0.200 \mathrm{C}$ \\
\hline 10 & 0.07000 & 0.07000 & 0.07000 & 0.07000 & 0.07000 & 0.07000 & $0.070 \mathrm{C}$ \\
\hline UE & NOVALUE & NOVALUE & NOVALUE & NOVALUE & NOVALUE & NOVALUE & NOVAL \\
\hline
\end{tabular}

FIG. 6.4 Include channels in Settings File N002_020. (DB Systemtechnik (2010)) 
The loaded channels will from now on be virtually available and can be dealt with.

To make the new $\mu\left(v_{s}\right)$ settings available to the algorithm it has to know which mueXX when to choose.

The present setting for the algorithm is to read a constant $\mu$ out of the Wheel-Rail Function Block in the Computing Function Block. So all that needs to be done is exchanging the constant $\mu$ variable with a series of "if loops" to make the algorithm choose which $\mu$ to include in the calculation for the maximal transferable braking force $F_{B}$. The set of constraints defines when which $\mu$, that was found under the settings of mueXX, will apply. These constrains chose by looking at the instance of braking at the $v_{s}$. If $v_{s}$ is bigger than $0 \mathrm{~km} / \mathrm{h}$ and smaller $1 \mathrm{~km} / \mathrm{h}$ then mue 01 will be entered in the calculus. If $v_{s}$ is bigger or equal to $1 \mathrm{~km} / \mathrm{h}$ and smaller $2 \mathrm{~km} / \mathrm{h}$ then mue 03 will be entered in the calculus ....and so on and so on.

$$
F_{B \max }=\mu_{B}\left(v_{s}\right) * F_{W A}
$$

$F_{B \max } \ldots \quad$ Maximal Force of Braking, in kN

$\mu_{B}\left(v_{s}\right) \ldots$ Developable adhesion during braking, depending on slip, dimensional unit 1

$F_{W A} \ldots \quad$ Force of Weight of axles, in $\mathrm{kN}$

By this procedure the fixed $\mu$ value will become a $\mu\left(v_{s}\right)$ value and be inserted in the equation of maximal braking force which is shown above. 


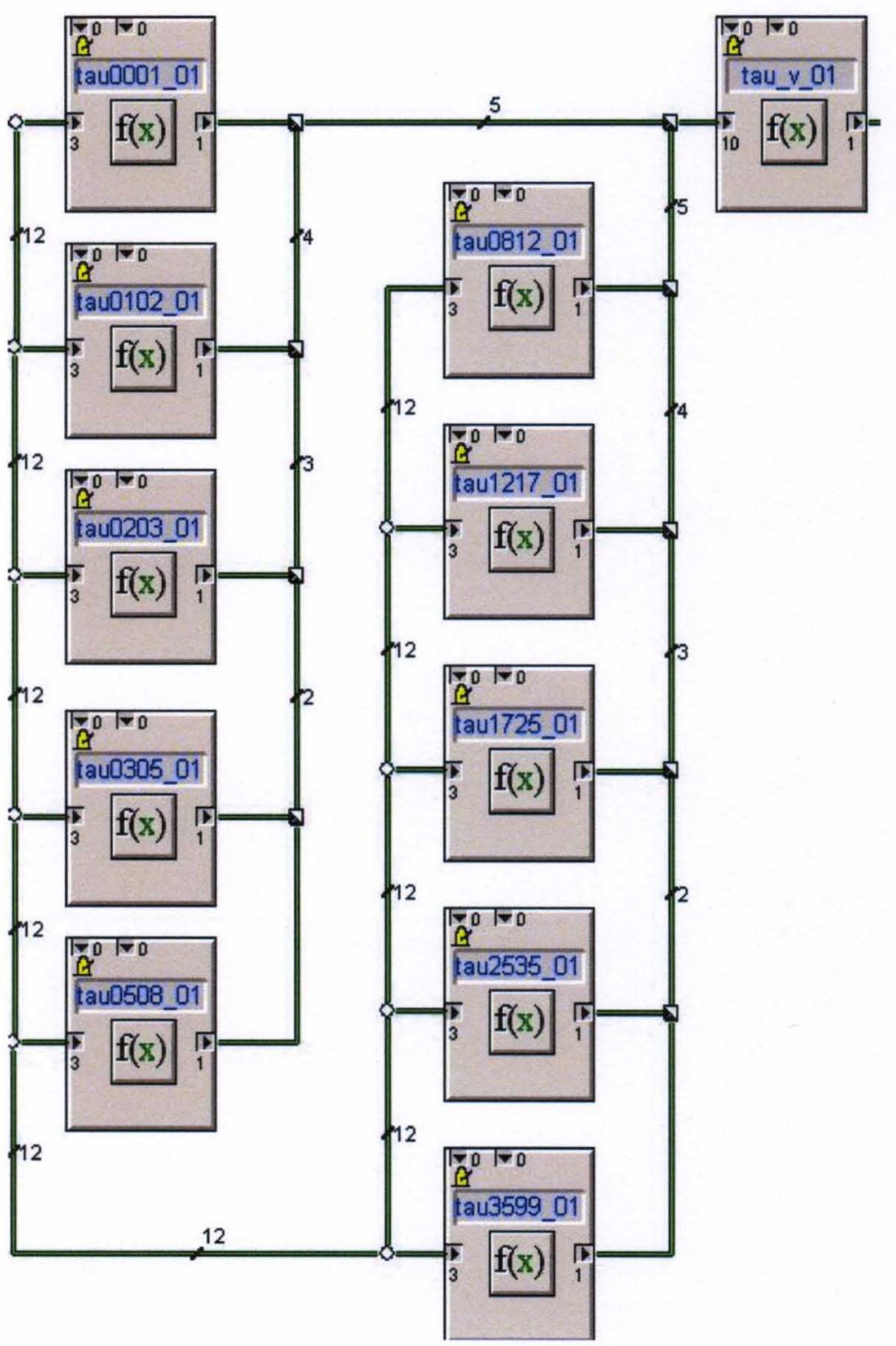

FIG. 6.5 Selection of mueXX dependent on vs. (DB Systemtechnik (2010))

The picture in FIG. 6.5 shows the selection functions in the DAC algorithm. The variable mueXX is here called $\operatorname{tau} X X$ which is just another name for the same variable. The precedent steps will have to be repeated for each of the four wheel sets since each of them can have its proper $\mu\left(v_{s}\right)$ value, hence it has it individual rate of wheel slip.

Once that is done the algorithm will be improved and ready to be tested. 


\subsection{Test of Improvement Effect}

For the test of the improved algorithm the new Settings File has to be called in the Excel file. When the Settings File is saved in the same directory as the unimproved file, it will be read at the start of the algorithm. FIG. 6.6 shows where the Settings Files are entered in the Excel file.

\begin{tabular}{|c|c|c|c|c|c|c|c|c|c|c|c|c|c|c|}
\hline 5 & Datum & Zeit & Art & V-IIr & $\begin{array}{c}\text { Vorgal: } \\
\text { Ant }\end{array}$ & Vorgabe-Datei & p & $\begin{array}{c}\text { DR- } \\
\text { Volumen }\end{array}$ & $\begin{array}{l}\text { Br- } \\
\text { Art }\end{array}$ & $\begin{array}{l}\text { Br- } \\
\text { Stilg }\end{array}$ & $v$ soll & $v$ ist & SB ist & sB korr \\
\hline 1550 & $01.03 .20 \mathrm{~V}$ & 10: $\mathrm{T}$ & $\nabla$ & $-\quad-$ & Neubec & der Prüfung & $\nabla$ & $\nabla$ & $\nabla$ & $\nabla$ & $\nabla$ & F & $\nabla$ & $\nabla$ \\
\hline 2047 & 23.03.2010 & $22: 23$ & V & 1875 & $\mathbf{R}$ & $11002 \_120 \_020$ & pR & 80 & SB & $\mathbf{P}$ & 120 & 122,1 & 676 & 653 \\
\hline 2048 & 23.03 .2010 & $22: 28$ & $|v|$ & 1876 & $\mathbf{R}$ & $11002 \_120 \_020$ & $p R$ & 80 & SB & $\mathbf{P}$ & 120 & 122,1 & 683 & 659 \\
\hline
\end{tabular}

FIG. 6.6 Call new Settings File "N002_020" in Excel.. (DB Systemtechnik (2010))

Now, to test the improvement effect of the new algorithm it is necessary to compare the old settings with the new ones. In order to do that, both settings will have to be run several times to get a statistically confirmative statement out of it. Afterwards the results of old an new can be compared.

In FIG. 6.7 the two adhesion curves are illustrated that will be compared within the improvement test. The curve "N001_070" is the original one with a constant $\mu$ value. The curve "N002_020" is the new curve with a $\mu\left(v_{s}\right)$ value. The initial $\mu\left(v_{s}\right)$ value at $v_{s}=$ $0,0 \mathrm{~km} / \mathrm{h}$ is 0,02 , respectively $\mu(0,0)=0,02$. 


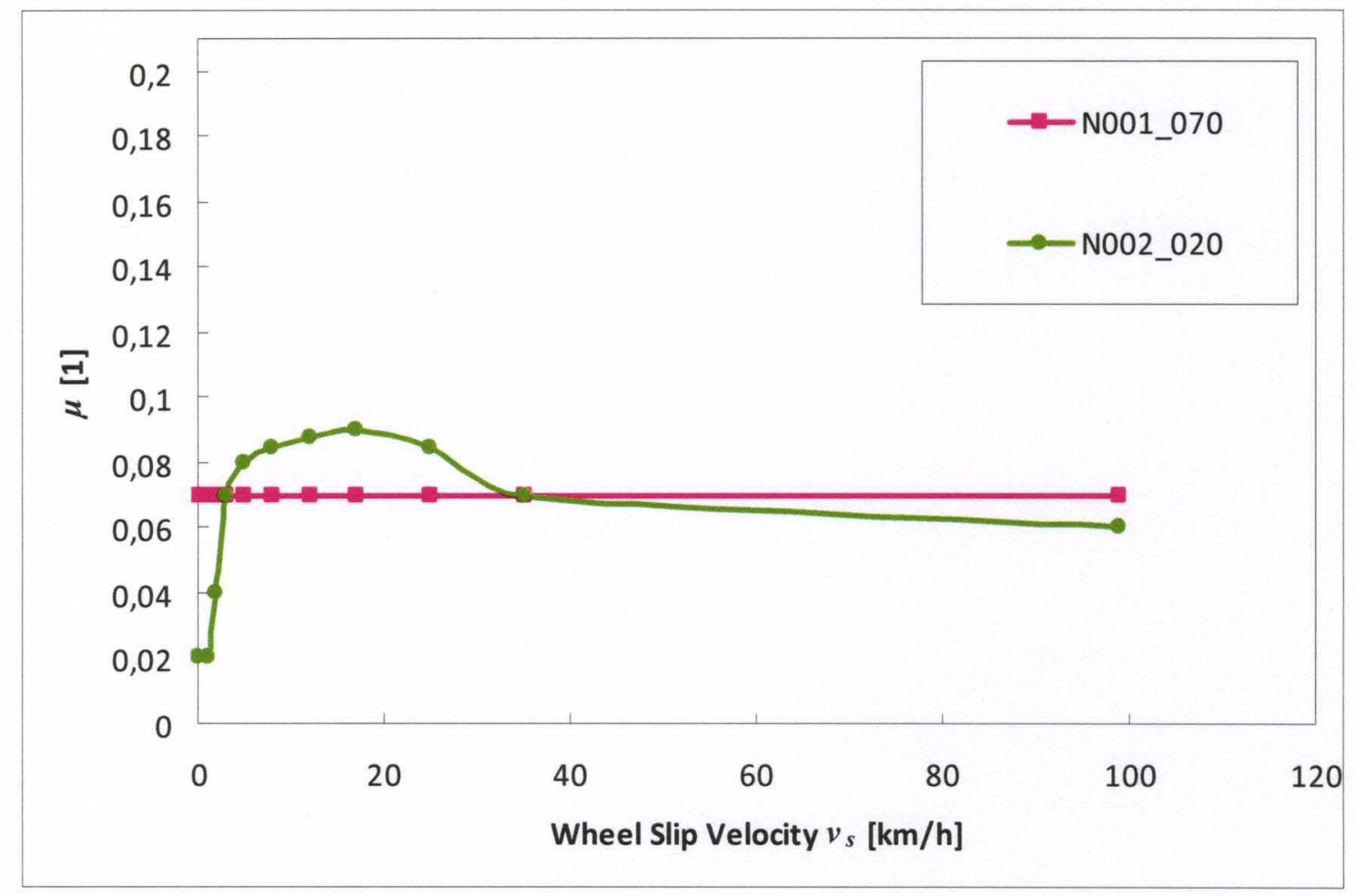

FIG. 6.7 The two Adhesion Curves to be compared. (DB Systemtechnik (2010))

\subsection{Findings}

After having run each setting for at least 20 times the following results could be obtained: The statistical evaluation of the comparison of N001 and N002 in the first instance based on the corrected to $120 \mathrm{~km} / \mathrm{h}$ initial speed braking distance, $\boldsymbol{s}_{\boldsymbol{B} \text { corr }} \mathbf{N} \mathbf{N 0 0 X} \mathbf{X}$. For the braking distance is the most important criteria on which the evaluation of the adequate function of a trains braking system is based on. The P and the R identify under which maximal pressure the brakes had been set during the braking. P is equal to 3,0 bar of $p C 01 \ldots 04$ and $\mathrm{R}$ is equal to 3,8 bar of $p C 01 \ldots 04$. $\mathrm{P}$ stands for passenger train and $\mathrm{R}$ stands for rapid train, of fast passenger train. $\mathrm{R}$ has to be chosen for every train that 
moves with a velocity higher than $120 \mathrm{~km} / \mathrm{h}$. P is normally limited to the usage up to 120 $\mathrm{km} / \mathrm{h}$. The TAB. 6.4 gives an overview of the most meaning statistical values.

TAB. 6.4 Statistical Evaluation of N001 and N002 compared, values in m.

\begin{tabular}{|c|c|c|c|c|}
\hline Statistics & $s_{\text {Bcorr }}$ N001_P & $s_{\text {Bcorr }}$ N002_P & $s_{\text {Bcorr }}$ N001_R & $s_{\text {Bcorr }}$ N002_R \\
\hline Mean Value & 688 & 657 & 638 & 580 \\
\hline Median & 688 & 657 & 637 & 580 \\
\hline Range min & 680 & 650 & 629 & 575 \\
\hline Range max & 696 & 671 & 655 & 587 \\
\hline ST Dev. & 4,50 & 4,06 & 6,20 & 3 \\
\hline Variance & 20,27 & 16,45 & 38,40 & 7,60 \\
\hline Mean -2 $\sigma$ & 678,58 & 648,69 & 625,82 & 574,59 \\
\hline Mean $+2 \sigma$ & 696,59 & 664,92 & 650,60 & 585,62 \\
\hline Confidence & $100 \%$ & $96 \%$ & $98 \%$ & $96 \%$ \\
\hline
\end{tabular}

The braking distance has to be lower than $730 \mathrm{~m}$. This standard has been set by the UIC. In both settings all the criteria of UIC standards have been met. Also the repetition confidence interval of $\pm 2 \sigma$, respectively $\boldsymbol{u}_{95} \leq 96 \%$, has been fulfilled.

It is remarkable that the braking distance of N002 is shorter than the one of N001. The TAB. 6.5 shows the deviation of $s_{B}$ between N001 and N002. 
TAB. 6.5 Braking distance $\boldsymbol{s}_{B}$ deviation between N001 and N002.

\begin{tabular}{l|l|c|c}
\hline Braking distance deviation & Braking distance deviation \\
$s_{\text {Bcorr }}$ N001_P & $s_{\text {Bcorr N002_P }}$ & $s_{\text {Bcorr N001_R }}$ & $s_{\text {Bcorr N002_R }}$ \\
\hline & $-31 \mathrm{~m}$ & $-58 \mathrm{~m}$ \\
\hline
\end{tabular}

The higher deviation of $-58 \mathrm{~m}$ with the $\mathrm{R}$ brake pressure is anticipatable, knowing that with higher pressure the brake cylinders fill faster, the brake reaction time is slightly shorter, and the braking force is higher.

When comparing the percentage of how much the wheel slip has been higher or equal to $10 \%$ throughout the braking process, it is noticeable that the percentage of N001 is always higher than the percentage of N002. Again both GM(n) Values answer to the UIC standard of a minimum of $35 \%$ throughout the braking. The values are displayed in TAB. 6.6.

TAB. 6.6 GM Value $-v_{s} \geq 10 \%$ over total braking, comparison of N001 and N002.

\begin{tabular}{l|c|c|c|c}
\hline \multirow{2}{*}{ Setting File } & \multicolumn{4}{|c}{ GM(n) Value - $\boldsymbol{v}_{\boldsymbol{s}} \geq 10 \%$} \\
& WS01 [\%] & WS02 [\%] & WS03 [\%] & WS04 [\%] \\
\hline N001_070_P & 63 & 61 & 36 & 68 \\
\hline N002_020_P & 49 & 59 & 40 & 61 \\
\hline N001_070_R & 74 & 71 & 66 & 62 \\
\hline N002_020_R & 62 & 66 & 42 & 69 \\
\hline
\end{tabular}


Also the absolute slip is lower for N002 than it is for N001. Whereupon both values are acceptable by UIC standards, for they are never exceeding $v_{\text {smax }}=-30 \mathrm{~km} / \mathrm{h}$.

The values are given in TAB. 6.7 below.

TAB. 6.7 Absolute Slip - $\boldsymbol{v}_{\text {smax }}$ over total braking, comparison of N001 and N002.

\begin{tabular}{l|c|c|c|c}
\hline \multirow{2}{*}{ Setting File } & \multirow{4}{|c}{$v_{\text {smax }}[\mathrm{km} / \mathrm{h}]$} \\
& WS01 & WS02 & WS03 & WS04 \\
\hline N001_070_P & -22 & -24 & -17 & -24 \\
\hline N002_020_P & -17 & -20 & -14 & -20 \\
\hline N001_070_R & -24 & -25 & -25 & -25 \\
\hline N002_020_R & -21 & -23 & -17 & -24 \\
\hline
\end{tabular}

Following two Figures (FIG. 6.8 and FIG. 6.9) provide the opportunity to compare an exemplary data chart of each setting, N001 and N002. It is noticeable that the velocities of all the four wheel sets run much steeper and also deeper into slip in the N001 chart than they are in setting N002 with a wheel slip depending adhesion value. On the other hand shows N002 less WSP valve activity leading to longer remainder in a slip band just over $10 \%$ slip. Both of these charts would be acceptable by the UIC standard. However the preference usually lies with the shorter braking distance. Which is provided by the N002 setting. 


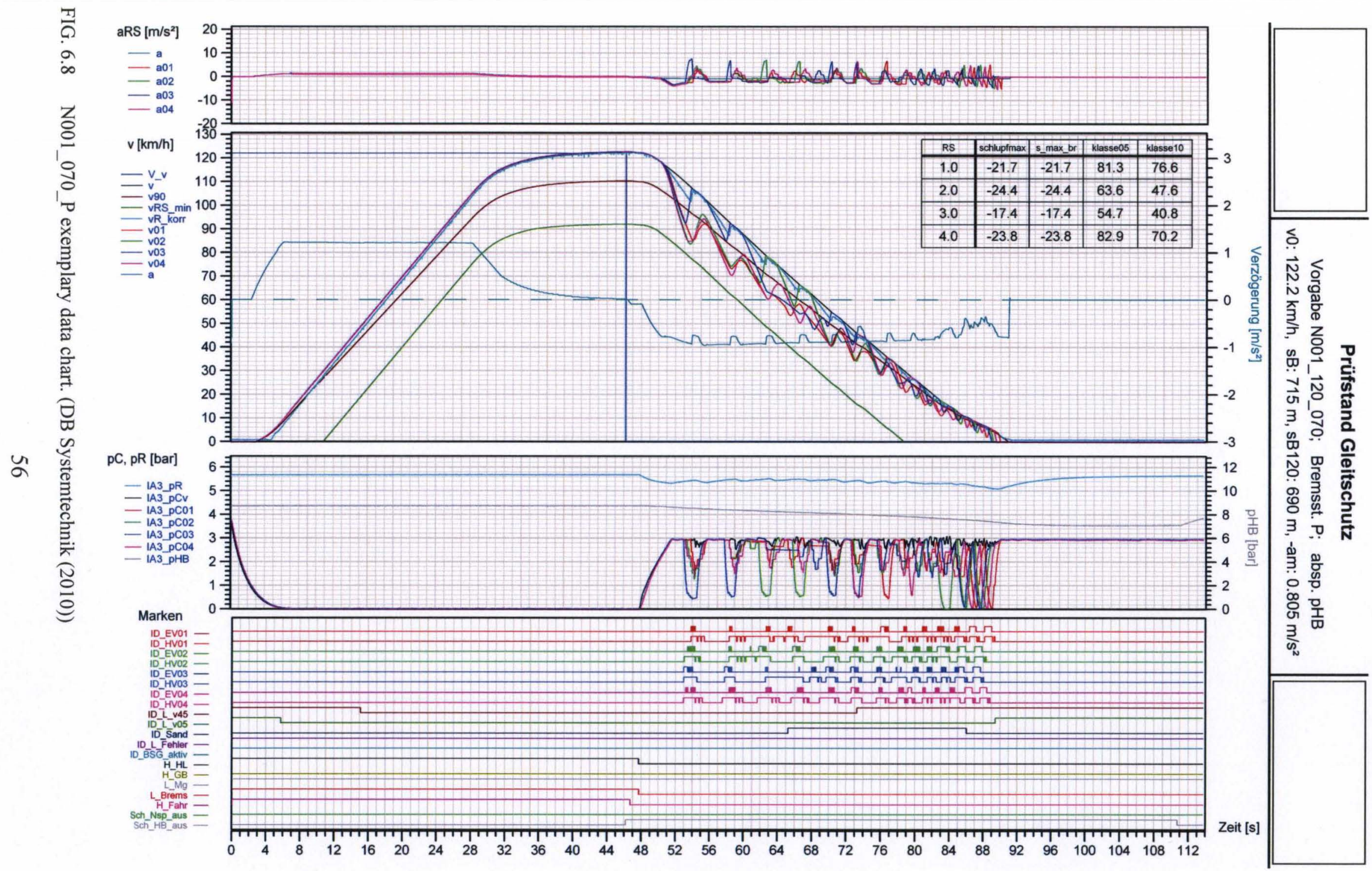




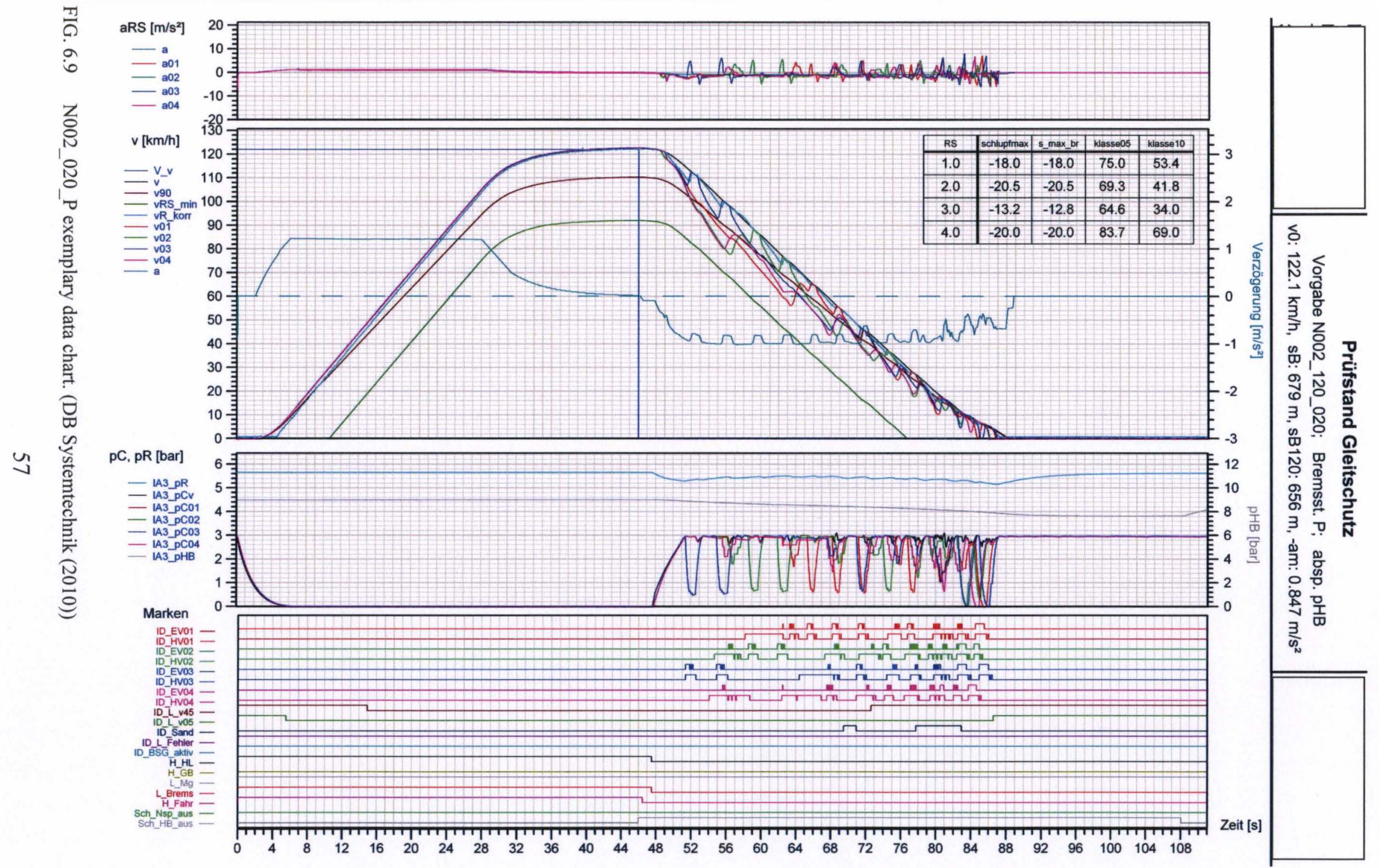




\section{CONCLUSIONS OF THE IMPROVEMENT}

Improving the Wheel Slide Protection Dynamometer by adding wheel slide velocity dependent adhesion curves to the algorithm has been successful. The WSPD algorithm computes now both simulations based on Setting Files with a constant $\mu$ value throughout the braking as well as Setting Files with a $\mu\left(v_{s}\right)$ value, that is dependent on the wheel slip velocity.

A test of the improvement shows that the difference between a N001 and a N002 setting is not severe. Both fulfill the UIC standards requirements for WSP device testing without restriction. However the braking distance of the N002 setting is in average $4,5 \%$ up to $9 \%$ shorter than the N001 setting's.

The two settings have confirmed a repetition confidence interval of $95 \%$ by $96 \%$ or higher.

During the braking of setting N001 is a higher percentage of wheel slip as well as a higher absolute maximal wheel slip notable. On the other hand shows the N002 less WSP valve activity and a longer remainder in a slip band of slightly more than $10 \%$ wheel slip. 


\section{DISCUSSION OF RESULTS}

The difference between the two tested simulation settings may not be very severe. Nevertheless is it remarkable how the Wheel Slide Protection Device is obviously finding the adhesion maximum. Disregarded of the lower initial and post maximal adhesion values provided by the N002 setting, is the WSP device able to achieve shorter braking distances than in the setting with an overall average of higher adhesion value. The only explanation for the shorter braking distances and the lower WSP valve activity can be the locating of the adhesion curve maximum. Provided this argumentation is flawless, the integration of wheel slip dependent adhesion curves is an important leap forward to testing WSP devices in an environment closer to reality.

However the full function of any WSP device can still be tested by means of constant $\mu$ values in the simulation. The demands of the UIC standards for WSP testing on simulation testbeds would still be met until further notice. Though the implementation of

$\mu\left(v_{s}\right)$ value curves into WSP simulations should lead to the adaptation of the standards to requiring higher defined testing algorithms on equal international bases as a necessaire. 


\section{FUTURE WORK}

The implementation of wheel slide velocity depending adhesion curves is only the beginning of many improvements that can and partially already have taken place. Directly connected to the adhesion curves the conditioning phenomenon by which the front running wheel sets alter the adhesion circumstances for those running behind. This phenomenon should be further researched and then also implemented in the Wheel Slide Protection Dynamometer Algorithm. The influence of the other forces and dynamics that come to play while braking is also not to be underestimated and, though already implemented in a rough way, they should be included in the simulation with more detail. The future main questions will remain the operating systems since MS Windows and DIAdem are not real-time capable. That could also imply a switch to newer BUS technology. Furthermore is the axle simulation not precise enough and thereby producing to much signal noise for the standard of today's WSP Devices. One first step will be the addition of electromagnetically shielded cables wherever possible.

Parallel to the construction of an up-to-date WSPD with a more flexible and exchangeable computing unit, should the pneumatic simulation modularized.

While improving the WSPD of DB Systemtechnik preparations for a European circle test of all the WSPDs in Europe is planned with the aim to equalize the international standards of WSP testing via simulation. 


\section{REFERENCES}

DB Systemtechnik (2010). Data of DB Systemtechnik-Brake Department Minden.

Berlin: Deutsche Bahn AG

Viereck, U. (2007). Entwicklung eines dynamischen Kraftschlussmodels als basis zur Optimierung von Gleitschutssystemen. University of Aachen RWTH

Lehna, H, Mahr, A. (2005). Literaturstudie zum Thema „Niedrighaftschluss“. Minden: Deutsche Bahn AG

UIC 541-05 (2005). Bremse - Vorschriften für den Bau der verschiedenen BremsteileGleitschutzanlage. Paris: UIC

UIC B164 RP2 (1990). Adhesion during braking, and anti-skid devices. Paris:UIC Office of Research and Experiments of International Union Railways

Wende, D. (2003). Fahrdynamik des Schienenverkehrs, $1^{\text {st }}$ Ed. Wiesbaden: Teubner Verlag 


\section{CURRICULUM VITAE}

NAME: $\quad$ Julian Holger Wallach

ADDRESS: $\quad$ Feilenstr. 10-12

33602 Bielefeld

Germany

DOB: $\quad$ Germany, Bielefeld - February $27^{\text {th }} 1982$

EDUCATION \&

- Diplom-Ingenieur (DHBW)

TRAINING

University of Applied Sciences of Baden Württemberg,, Lörrach, Germany

$2005-2009$

- Bachelor of Science with honours

University of Applied Sciences, Basle, Switzerland

$2005-2009$

- Bachelor of Engineering with honours

Open University, Milton Keynes, United Kingdom

$2005-2009$

- Licence en Sciences et Technologie

Université d'Haute Alsace, Mulhouse, France

2005-2009 
- Certificate as Instructor for Apprentices in Mechatronics Chamber of Commerce and Industry Cologne, Cologne, Germany

2004

- Certified Skilled Worker in Mechatronics

Deutsche Bahn AG, DB Training, Duisburg, Germany

Chamber of Commerce and Industry Dortmund, Dortmund, Germany

2001-2004

- Foreign Language Correspondence Clerk in English Berufskolleg der Friedrich von Bodelschwingschen Anstalten Bethel, Bielefeld, Germany

1999-2002

- A-Levels

Berufskolleg der Friedrich von Bodelschwingschen Anstalten Bethel, Bielefeld, Germany

1998-2001

- Exchange Student $5^{\text {eme }}$ Secondaire École Secondaire Felix-Leclerc, Montréal, Canada 1998-1999

PUBLICATIONS: - Impact of Surface Structures on the Inline Vision Inspection of Antireflection Coatings

Presented at the 24th European PV Solar Energy Conference and Exhibition, 21 -25 September 2009, Hamburg, Germany

Paper by A. Krieg, J. Wallach, S. Rein

Representing The Fraunhofer Institute for Solar Energy Systems ISE, Freiburg, Germany

2009 
- Evaluation of an Inline-Process for Optical Quality Control of Antireflection Coatings

Diploma Thesis at the Fraunhofer Institute for Solar Energy Systems ISE, Freiburg, Germany

2008-2009

\section{PROFESSIONAL}

EXPERIENCE:
- Deutsche Bahn AG - DB Systemtechnik, Minden, Germany

Test Engineer - Rail Vehicle Brake Systems

Since 2009

- Project Burkina08

Organization and Execution of a social aid project establishing solar panels and lights in two schools and a library in Burkina Faso

2007-2008

- Deutsche Bahn AG - DB Schenker Rail, Mainz, Germany

Student Trainee - European Production Network 2005-2009

- Deutsche Bahn AG - DB Training, Cologne, Germany Instructor for Apprentices in Mechatronics 2004-2005

- Deutsche Bahn AG - DB Training, Duisburg, Germany Apprenticeship as Skilled Worker in Mechatronics 2001-2004

- Numerous Internships in the fields of Manufacturing Industry, Craft, and International Trade Departments In Germany, Canada, France, Switzerland, Italy, 1997-2009 